\section{A) Check for updates}

Cite this: Phys. Chem. Chem. Phys., $2021,23,8118$

Received 4th February 2021 Accepted 18th March 2021 DOI: $10.1039 / \mathrm{d} 1 \mathrm{cp} 00535 \mathrm{a}$ rsc.li/pccp

\title{
Ultrafast photoinduced dynamics in Prussian blue analogues
}

\author{
Kyle Barlow (D) and J. Olof Johansson (D)*
}

\begin{abstract}
New magnetic materials and methods for controlling them are needed to improve data storage technologies. Recent progress has enabled optical detection and manipulation of spins in molecule-based magnets on the femtosecond timescale, which is promising for both increasing the read/write speed but also the data storage density. Experimental developments in femtosecond X-ray free-electron lasers (XFELs) and magneto-optics, in combination with theory advances, have opened up several new avenues to investigate molecule-based magnets. This review discusses the literature concerning ultrafast photoinduced dynamics in Prussian blue analogues (PBAs), which are molecule-based magnets. In PBAs spin-flips and lattice distortions can happen on the 100 fs timescale, which in some analogues lead to photoinduced changes in the long-range magnetic order. The literature and themes covered in this review are of relevance for ultrafast optical control of new multifunctional materials.
\end{abstract}

\section{Introduction}

In data storage devices, information is recorded by manipulating magnetically ordered materials. Given the growing demand for faster and more efficient processing of large data sets in modern society, new materials and methods are being developed to improve the speed of the write process. In particular, the use of femtosecond (fs) laser pulses to control spins in magnetically ordered materials would allow for very fast data processing.

EaStCHEM School of Chemistry, University of Edinburgh, David Brewster Road, EH9 3FJ, Edinburgh, UK. E-mail: olof.johansson@ed.ac.uk

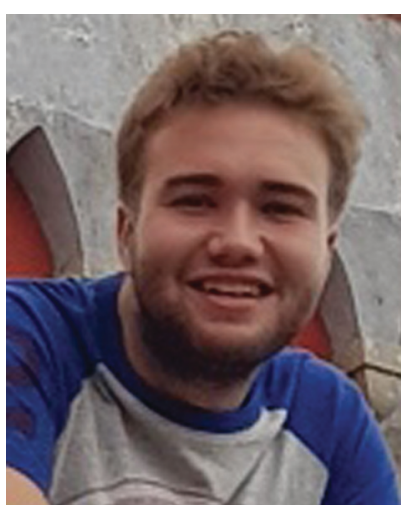

Kyle Barlow
Kyle completed his undergraduate degree in Chemical Physics at the University of Edinburgh in 2020. In his final-year project in the Johansson group, he studied ultrafast dynamics in Prussian blue analogues. Kyle is now working on the ultrafast dynamics in transition metal complexes particularly looking at single molecule magnets.

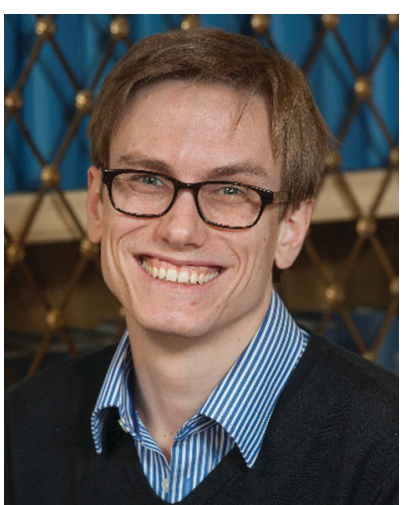

J. Olof Johansson
The problem of how fast light can change the spin state of molecules has been discussed during the last 25 years, ${ }^{1-3}$ enabled by the development of fs lasers. In particular, inorganic complexes have been extensively studied and it is now wellknown that intersystem crossing (ISC), i.e. a change in electronic state with different spin multiplicity, can happen on the order of $100 \mathrm{fs}$ in $\left[\mathrm{Ru}(\mathrm{bpy})_{3}\right]^{2+}$ (ref. 1 and 4) and $\mathrm{Cr}(\mathrm{acac})_{3}$ (ref. 5). One of the most studied systems are Fe(II) complexes. It has been shown that it is possible to change the spin quantum number from $S=0$ to $S=2$ in $c a$. 100 fs by absorbing just one photon via the metal-to-ligand charge-transfer (MLCT) transition. ${ }^{6-10}$ This leads to a fast depopulation of the MLCT state into the ligand of Edinburgh. In 2016 Olof became a member of the RSE Young Academy of Scotland. 
manifold (or metal-centred states) with different spin quantum numbers. A lot of the recent understanding of the very fast spin changes in inorganic complexes comes from the development of new techniques, such as X-ray free-electron lasers (XFELs) ${ }^{8,9,11-16}$ (see a recent review by Chergui and Collet $^{17}$ ), table-top X-ray sources ${ }^{18,19}$ and ultrafast electron diffraction. ${ }^{20,21}$ Furthermore, developments in computational methods have been essential. ${ }^{22-29}$ These advances have enabled chemical control of the lifetime of the excited states. ${ }^{11,30}$ Similarly, it was recently shown that wavepackets can be controlled via synthetic design to both slow down the ISC rate to stabilise the MLCT state in Fe(II) complexes ${ }^{31}$ and to change the anisotropy in Mn-based single-molecule magnets. ${ }^{32}$ These advances open up possibilities to control the spin and structural evolution in the excited state of paramagnetic metal complexes. Moving towards larger systems, solvated $[2 \times 2]$ $\mathrm{Fe}(\mathrm{II})$ metallogrid complexes were recently studied using optical and infrared absorption spectroscopy, and X-ray emission spectroscopy. ${ }^{33}$ In the condensed phase, sub-ps ISC has also been demonstrated in molecular crystals of $\mathrm{Fe}(\mathrm{III})^{12,34,35}$ and $\mathrm{Fe}(\mathrm{II}){ }^{14,36}$ This work has led to some very exciting results, for example, that the cooperative effects of spin-crossover (SCO) in crystals and nanoparticles can lead to the possibility to control and stabilise ultrafast photoinduced phase transitions. ${ }^{37-39}$

Spins in semiconductors can be controlled on ultrafast timescales by exciting spin-polarised carriers using circularly polarised light and where the sign of the spin polarisation depends on the helicity of the pump pulse. ${ }^{40}$ This is detected using magneto-optical polarisation techniques, such as Faraday rotation, which are sensitive to the magnetisation of the sample and provide fs time resolution which is not possible with other techniques such as electron paramagnetic resonance. There have been several exciting breakthroughs such as the observation of coherent transfer of spin polarisation from photocarriers to localised magnetic moments on $\mathrm{Mn}^{2+}$ ions in magnetic heterostructures ${ }^{41}$ and even between molecularly bridged quantum dots. ${ }^{42}$ The field has now moved on to controlling spins of impurities in, for example diamond and silicon to create new quantum technologies. ${ }^{43}$

There has also been an impressive development of ultrafast control of materials with long-range magnetic order. ${ }^{44-46}$ This interest was initiated by the surprising discovery that fs laser pulses could affect long-range magnetic order on the $100 \mathrm{fs}$ timescale by Beaurepaire et al. ${ }^{47}$ Long-range magnetic order is key for data storage applications, because the non-volatility means that the information is stored after the laser pulse, in contrast to the work on semiconductors mentioned above. It is now possible to completely reverse the magnetisation direction using a single fs laser pulse in thin films of some metallic, ${ }^{44}$ and, more recently, dielectric ${ }^{48-50}$ materials. Interestingly, the magnetisation is observed to be quenched on timescales faster than the spin-phonon relaxation time, which raised the question about the conservation of angular momentum if the phonons are not engaged in the first $100 \mathrm{fs}$ (spin is, of course, a form of angular momentum). ${ }^{51-55}$ However, recently it has been shown that strain waves in magnetic Fe films can be launched on similarly fast timescales and which accommodate the conservation of angular momentum. ${ }^{56}$ These findings highlight the complicated interaction between spins, electrons, nuclear motion, and photons. It is an important problem since fast switching of the magnetisation is needed for recording data, and the processes in hard drives are limited to the nanosecond (ns) timescale. New experimental approaches, with fs temporal resolution, are also being pursued in this field, such as XFELs, ${ }^{56-60}$ X-ray magnetic circular dichroism (XMCD), ${ }^{61,62}$ and spin-resolved photoemission. ${ }^{63,64}$

Somewhere in between the detailed understanding at the molecular level and the complex multi-dimensional interactions in a magnetic solid, lies molecule-based materials. These are made from molecular building blocks and, by using the right linker, it is possible to form long-range magnetic order. ${ }^{65}$ They open up possibilities to explore how ISC at the local scale can influence long-range magnetic order, as has been shown for the cyano-bridged $\mathrm{Fe}_{2}\left[\mathrm{Nb}(\mathrm{CN})_{8}\right] \cdot(4 \text {-pyridinealdoxime })_{8} \cdot 2 \mathrm{H}_{2} \mathrm{O}$ (although not on the ultrafast timescale). ${ }^{66}$ The approach using molecular building blocks also have the advantage of chemical flexibility, which could be used to tune and optimise materials showing, for example, photomagnetic properties. ${ }^{67}$ Now is the time to explore these materials because of the recent developments in ultrafast experimental and computational methods mentioned above.

In this review, we discuss ultrafast dynamics taking place in molecule-based magnets of Prussian blue (PB) and its analogues. ${ }^{68}$ Prussian blue analogues (PBAs) are cyanometalate coordination polymers and have a face-centred cubic structure with general formula $\mathrm{M}_{x} \mathrm{~A}_{y}\left[\mathrm{~B}(\mathrm{CN})_{6}\right]_{z} \cdot n \mathrm{H}_{2} \mathrm{O}$ where $\mathrm{M}$ is an alkali metal and $\mathrm{A}$ and $\mathrm{B}$ are transition metal (TM) ions (Fig. 1). ${ }^{68}$ The mixed-valence TM ions are bonded via negatively charged cyanide bridges. The B ion is coordinated to six carbon atoms and has a low spin configuration because of the large ligandfield strength in the carbon pocket. The A ion is coordinated to 6 nitrogen atoms and is either high- or low spin due to the weaker ligand-field strength in the nitrogen pocket. Of course, depending on the stoichiometry, the TM can have less than 6 neighbours and be coordinated with water. One typically encounters a $1: 1(x=1)$ or $3: 2$ ratio $(x=0)$ of $\mathrm{A}$ and $\mathrm{B}$. It is the mixed valency and superexchange interaction through the cyanide bridge that is the source of magnetic ordering in PBAs. The advantages of PBAs include room-temperature magnetic ordering (although limited to the $\mathrm{V}-\mathrm{Cr} \mathrm{PBA}$ ), ${ }^{69,70}$ tuneability of magnetic ${ }^{71-74}$ and optical properties, ${ }^{75-78}$ as well as multifunctional properties such as photomagnetism ${ }^{79-81}$ and electrochromism. ${ }^{82-84}$

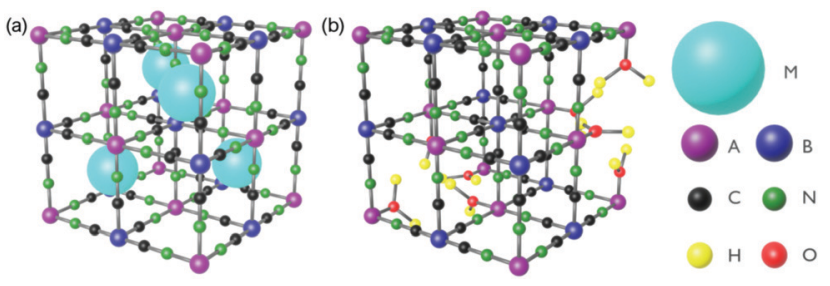

Fig. 1 The general structure of PBAs with (a) $1: 1$ and (b) $3: 2$ stoichiometry of $A$ and $B . M$ is a cation and $A$ and $B$ are transition metal ions. 
There is an on-going effort into developing the quality of PBAs, as was recently reviewed. ${ }^{85,86}$ It is also possible to form thin films ${ }^{83,84,87-93}$ and even heterostructures of these materials. ${ }^{94-96}$ Magnetic heterostructures are actively explored in the ultrafast magnetism community to create fs spin-polarised currents. ${ }^{97}$ There are already several excellent reviews on PBAs. ${ }^{67,70,77,98-100}$ We also note a wealth of other cyano-bridged materials with very exciting photomagnetic properties. ${ }^{67,101}$

The primary photophysical processes in molecular materials happen on the fs timescale, and so we have attempted to collate studies concerning ultrafast dynamics in PBAs (occurring on the fs/ps timescales). For these timescales, the most used method is transient absorption (TA). This is a pump-probe technique whereby a laser pulse excites the sample and a second, delayed, laser pulse probes the photoexcited sample. The probe pulse can be quasi-monochromatic or consist of a broadband continuum spanning typically from 350-700 nm. IR probes are also possible, as has been explored for some PBAs taking advantage of the strong asymmetric cyanide stretch. ${ }^{102}$ In the data, one typically plots either the spectra of the excited species for different time delays or sometimes the decay kinetics of the signal at a particular wavelength/spectral feature. In the TA spectra, one typically observes excited-state absorption (ESA), that is absorption from the excited electronic state, or ground-state bleach (GSB), which is loss of absorbing chromophores in the ground state and results in more light reaching the detector. The GSB typically mirrors the static absorption spectrum. It is also possible to observe stimulated emission, which has the same sign as GSB in the TA spectrum because more light reaches the detector than for an un-pumped sample.

We start by giving a general introduction to the optical properties of cyano-bridged dimers, which are the buildingblocks of PBAs and briefly mention work that has been done on ultrafast dynamics in these. We will then build the complexity and move on to cover the optical properties of PBAs and studies of ultrafast dynamics. We cover literature concerning the Fe-Fe, Co-Fe, Mn-Fe, and V-Cr PBAs.

A key picture that emerges is that the dynamics after photoexcitation often results in either fast back-electron transfer (BET) or trapped charge-transfer (CT) states after CT excitation. In either case, fast excitation of the cyanide stretch modes and other vibrational modes occurs. If the population of metal-centred antibonding $\mathrm{e}_{\mathrm{g}}$ orbitals is changed, typically long-range structural distortions take place. This is to some extent determined by the ability of the solid to accommodate the changes to bond lengths after $e_{\mathrm{g}}$ population dynamics, highlighting the importance of electron-phonon coupling.

\section{Cyano-bridged dimers}

Cyano-bridged dimers of the type A-NC-B, where A and B are TM ions, are the building blocks of PBAs. It is therefore interesting to first survey work that has been done of these model systems. The electronic structure of mixed-valence cyanide-bridged dimers is typically classified as Class II (Robin and Day), just like PBAs. ${ }^{103}$ In the molecules of interest, the sites are chemically different - either they are in different oxidation states or they comprise different elements. Class II implies that the $3 \mathrm{~d}$-electrons are not fully localised on one metal ion but some degree of delocalisation via the cyanide bridge between the two metal ions occurs. For Prussian blue, the ground state wavefunction (fully localised on one metal ion) has a $c a .1 \%$ contribution from the wavefunction corresponding to the electron localised on the other metal ion. ${ }^{103}$ In dimers, the strongest optical transition in the visible is typically the metal-tometal charge-transfer (MMCT) transition, which corresponds to transferring an electron from one site to another. The oscillator strength of the transition is proportional to the delocalisation between the two ions, which in turn depends on the bond length, and mixing and energy difference between the fully localised state and the transferred-electron-state. ${ }^{103,104}$

One early study was on $\left[\left(\mathrm{NH}_{3}\right)_{5} \mathrm{Ru}^{\mathrm{III}}-\mathrm{NC}-\mathrm{Ru}^{\mathrm{II}}(\mathrm{CN})_{5}\right]^{-}(\mathrm{RuRu})$ and $\left[\left(\mathrm{NH}_{3}\right)_{5} \mathrm{Ru}^{\mathrm{III}}-\mathrm{NC}-\mathrm{Fe}^{\mathrm{II}}(\mathrm{CN})_{5}\right]^{-}(\mathrm{RuFe})$, where the MMCT was excited at $795 \mathrm{~nm} .{ }^{105}$ The MMCT leads to an intramolecular electron transfer, producing $\mathrm{Ru}^{\mathrm{II}}$ in the ammonia pocket and $\mathrm{Ru}^{\mathrm{III}}$ in the cyanide pocket (and similarly for RuFe). It was observed that back-electron-transfer (BET) occurred on $85 \pm 10 \mathrm{fs}$ in $\mathrm{H}_{2} \mathrm{O}$ and $122 \pm 20$ fs in $\mathrm{D}_{2} \mathrm{O}$ for both complexes. The electronic dephasing time was shorter than the instrumental temporal resolution of 20 fs. The authors observed oscillations superimposed on the decay kinetics, with frequencies corresponding to 170,270 , and $488 \mathrm{~cm}^{-1}$. These modes were assigned as solvent librational degrees of freedom that are coupled to the CT process. They also observed that some degree of vibrational coherence is maintained even during the BET, with a dephasing time on the order of $300 \mathrm{fs}$ (i.e. longer than the $100 \mathrm{fs}$ BET). This is indicative that energy is deposited into the $\mathrm{CN}^{-}$stretch modes. The energy was found to be dissipated to the solvent with a time constant of $880 \pm 160$ fs for $\mathrm{RuRu}$ in $\mathrm{H}_{2} \mathrm{O}$, although this time constant depends on the excitation energy since excess energy led to longer decay times (pumping at the red or blue edge of the MMCT). Several other studies have now established that the electron transfer associated with the MMCT transition in dimers is strongly coupled to the solvent and the nuclear degrees of freedom of the molecule, ${ }^{106-108}$ which has also been confirmed by time-resolved IR studies. ${ }^{109,110}$ Moving to extended chains, Su et al. have studied $\mathrm{Ru}^{\mathrm{II}}-\mathrm{CN}-\mathrm{Ru}_{2}^{\mathrm{III}, \mathrm{III}}-\mathrm{CN}-\mathrm{Ru}^{\mathrm{II}}{ }^{111}$ who found that the lifetime of the CT state could be controlled by chemical tuning of substituent group of the metal ions. Khalil's group have studied $(\mathrm{NC})_{5} \mathrm{Fe}^{\mathrm{II}}-\mathrm{CN}-\mathrm{Pt}^{\mathrm{IV}}\left(\mathrm{NH}_{3}\right)_{4}-\mathrm{NC}-\mathrm{Fe}^{\mathrm{II}}(\mathrm{CN})_{5}$ complexes using advanced time-resolved spectroscopies. ${ }^{110,112,113}$ They found that intramolecular vibrational relaxation dynamics happens on the ps timescale and that the dynamics of the vibrational relaxation depends on the spatial localisation of the vibrational mode and how it couples to the solvent. ${ }^{110}$

Macpherson et al. have studied dimers of cyano-bridged $\left[\mathrm{LCo}^{\mathrm{III}}-\mathrm{NC}-\mathrm{Fe}^{\mathrm{II}}(\mathrm{CN})_{5}\right]^{-}$, where $\mathrm{L}$ is a pentadentate macrocyclic pentaamine or triamine-dithiaether. ${ }^{114}$ This dimer is an important model system for photomagnetic PBAs, since the Co-Fe PBA can be optically excited from a paramagnet to ferrimagnet, ${ }^{79,115}$ as will be discussed below. In this process, MMCT from $\mathrm{Fe}^{\mathrm{II}}$ to $\mathrm{Co}^{\mathrm{III}}$ 

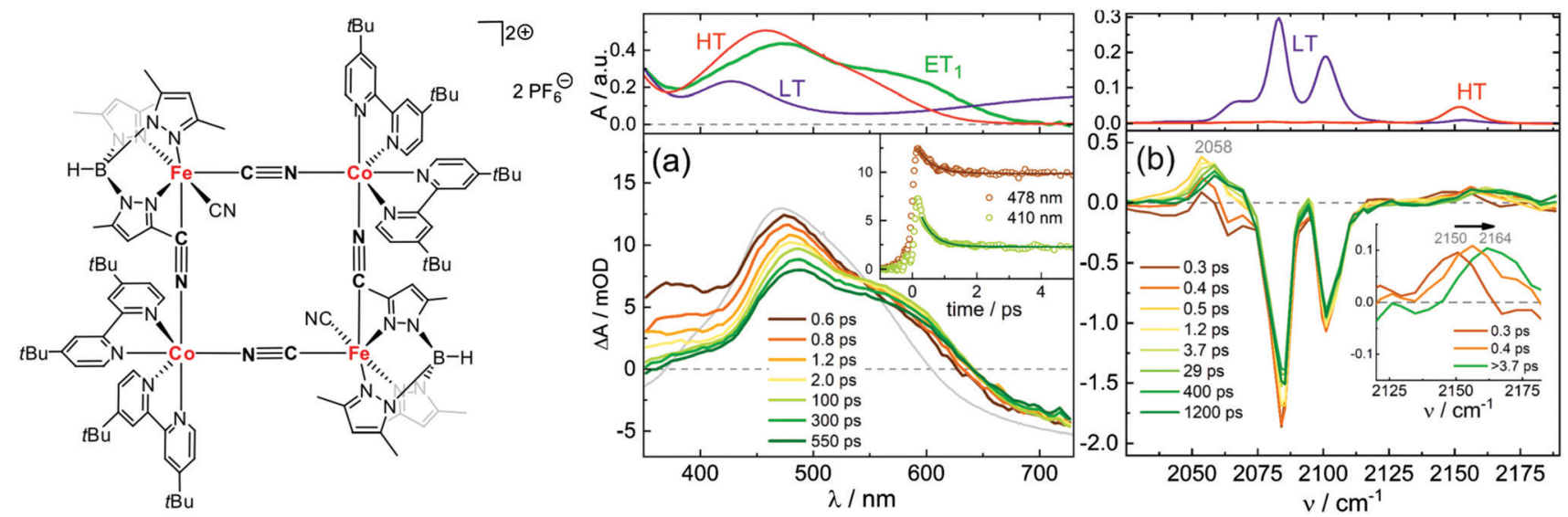

Fig. 2 Structure of $\left[\left(\mathrm{CO}_{\mathrm{LS}}^{\prime \prime \prime}\right)_{2}\left(\mathrm{Fe}_{L S}^{\| \prime}\right)_{2}\right]$ together with transient absorption data in acetonitrile at $-30{ }^{\circ} \mathrm{C}$ with (a) UV-visible probe and $775 \mathrm{~nm}$ pump wavelength and (b) IR probe and $800 \mathrm{~nm}$ pump. The top panels show the static absorption spectra in the $\mathrm{LT}\left(-30^{\circ} \mathrm{C}\right)$ and $\mathrm{HT}\left(30^{\circ} \mathrm{C}\right)$ phases. The green line (ET1) corresponds to the calculated spectrum of the one-electron transfer product [CoLS $\mathrm{Le}_{L S}^{\prime \prime} \mathrm{CO} \mathrm{HS}_{\mathrm{HS}}^{\prime \prime} \mathrm{EeS}_{\mathrm{LS}}^{\prime \prime \prime}$. The bottom panels show the time-resolved spectra at selected time delays. The grey line shows the difference between the HT and LT static spectra. Reprinted with permission from Zimara et al. Inorganic Chemistry, 2021, 60, 449-459. ${ }^{116}$ Copyright 2021 American Chemical Society.

(low-spin, LS) leads to a fast reorganisation of the spin state on the $\mathrm{CO}^{\mathrm{II}}$ site via ISC and forms $\mathrm{Co}^{\mathrm{II}} \mathrm{Fe}^{\mathrm{III}}$ in the high-spin (HS) state. After exciting the MMCT, Macpherson et al. observed ESA below $400 \mathrm{~nm}$ in the dimers assigned to metal-centred transitions from $\mathrm{Fe}^{\mathrm{III}}$, which gives a spectral signature of the CT state. Using a combination of ns and fs TA, and at 11 and $293 \mathrm{~K}$, they concluded that the $\mathrm{LS} \mathrm{Co}^{\mathrm{II}} \mathrm{CT}$ state undergoes fast BET on a ps timescale, whereas the $\mathrm{HS} \mathrm{Co}^{\mathrm{II}}$ state lived for a longer time at low temperatures ( $c a .10 \mathrm{~ns}$ ). Recently Zimara $e t$ al. showed using both TA and time-resolved IR that in a $\mathrm{Co}^{\mathrm{II}} \mathrm{Fe}^{\mathrm{III}}$ dimer, where $\mathrm{Co}^{\mathrm{II}}$ is $\mathrm{HS}$ and $\mathrm{Fe}^{\mathrm{III}} \mathrm{LS}$, photoexcitation of the MMCT band leads to a short-lived CT state (3.8 ps), followed by vibrational cooling in the hot electronic ground state. ${ }^{116}$ Interestingly, they also studied the square-type complex $\mathrm{Fe}_{2} \mathrm{Co}_{2}$ in both $\left[\left(\mathrm{Co}_{\mathrm{LS}}^{\mathrm{III}}\right)_{2}\left(\mathrm{Fe}_{\mathrm{LS}}^{\mathrm{II}}\right)_{2}\right]$ and $\left[\left(\mathrm{CO}_{\mathrm{HS}}^{\mathrm{II}}\right)_{2}\left(\mathrm{Fe}_{\mathrm{LS}}^{\mathrm{III}}\right)_{2}\right]$ states (Fig. 2). After excitation at around $800 \mathrm{~nm}$, they observed a TA spectrum that did not match perfectly with the difference between the steady-state spectra of the two phases, which would have indicated a complete conversion to the HT phase. Instead, they could conclude that a oneelectron transfer takes place on one of the Co-Fe pairs by comparing to calculations. They conclude that a spin-crossover to a metastable tetranuclear $\left[\mathrm{Co}_{\mathrm{LS}}^{\mathrm{III}} \mathrm{F}_{\mathrm{LS}}^{\mathrm{II}} \mathrm{Co}_{\mathrm{HS}}^{\mathrm{II}} \mathrm{Fe}_{\mathrm{LS}}^{\mathrm{III}}\right]$ product takes place in $400 \mathrm{fs}$, which has a lifetime of over $1 \mathrm{~ns}$ at $-30{ }^{\circ} \mathrm{C}$. The time-resolved IR spectra in Fig. 2(b) also confirm this assignment as the intermediate peaks do not correspond to the HT phase static spectrum. We will return to the Co-Fe PBA later on in the review.

\section{Prussian blue and its analogues}

PBAs are also Class II delocalised mixed-valence compounds. The delocalisation leads to magnetic ordering via the superexchange interaction but also intense colours via MMCT transitions (which also depend on the delocalisation). Examples of colourful PBAs are Fe-Fe PB (which of course has been used as a pigment for centuries), ${ }^{117} \mathrm{~V}-\mathrm{Cr},{ }^{69,76}$ and $\mathrm{Fe}-\mathrm{Cr}{ }^{75}$ However, because of lower symmetry in the solid (vacancy sites), or simply a larger number of chromophores, other transitions compete, and it is possible to also observe $\mathrm{d}-\mathrm{d}$ transitions. This makes the assignment of the optical transitions more complicated, as in the case of $\mathrm{Cr}-\mathrm{Cr}^{75,90,93,118}$ and $\mathrm{Co}-\mathrm{Fe}^{119-121}$ PBAs.

\subsection{Fe-Fe PB}

The ultrafast dynamics of the Prussian blue $\mathrm{Fe}_{4}{ }^{\mathrm{III}}\left[\mathrm{Fe}^{\mathrm{II}}(\mathrm{CN})_{6}\right]_{3}$ (PB) was first investigated in 1995 by Arnett et al. ${ }^{122}$ Although the "original" $\mathrm{PB}$ discussed in this section is only ferromagnetic below $5 \mathrm{~K}$ due to the diamagnetic $\mathrm{Fe}^{\mathrm{II}}$ ion, the early charge dynamics still lend important insight to other PBAs. Using polarisation dependent pump-probe studies, Arnett et al. investigated the optical excitation, electronic dephasing and vibrational coherences within colloidal Prussian blue particles suspended in water. The $800 \mathrm{~nm}$ pump excited the MMCT $\left(\mathrm{Fe}^{\mathrm{II}}\right.$ to $\left.\mathrm{Fe}^{\mathrm{III}}\right)$ band and the probe beam, of same wavelength, measured the change of transmittance through the particles at different time delays using light with parallel or perpendicular polarisation directions with respect to the pump beam polarisation direction. This type of anisotropy measurement can give information if the excited state is localised or delocalised. ${ }^{123-125}$ The faith of the excited state within the first $50 \mathrm{fs}$ can be seen from a fast decay in transmittance in the parallel probe and an increase in the transmittance of the perpendicular probe (Fig. 3). Both these signals were attributed to ground state bleach (GSB) of the MMCT band. Calculating the polarisation anisotropy of the time-resolved absorption gave a decay constant of 15 fs of the anisotropy. During optical excitation, the electron density is transferred from the $\mathrm{Fe}^{\mathrm{II}}$ ion, with electron configuration $\mathrm{t}_{2 \mathrm{~g}}{ }^{6} \mathrm{e}_{\mathrm{g}}{ }$, to only one of the six surrounding $\mathrm{Fe}^{\mathrm{III}}$ $\left(t_{2 g}{ }^{3} \mathrm{eg}_{\mathrm{g}}{ }^{2}\right)$ ions in which the transition dipole moment of the MMCT is aligned with the polarisation of the pump laser. Therefore, the immediate peak in the parallel probe transmittance is due to GSB of the MMCT. No change in signal was recorded in the perpendicular probe in the very early time delays (Fig. 3a), as 


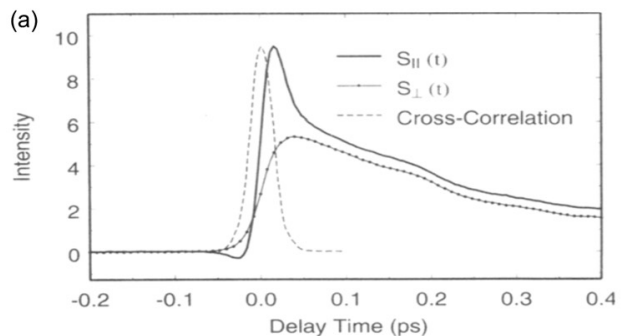

(b)
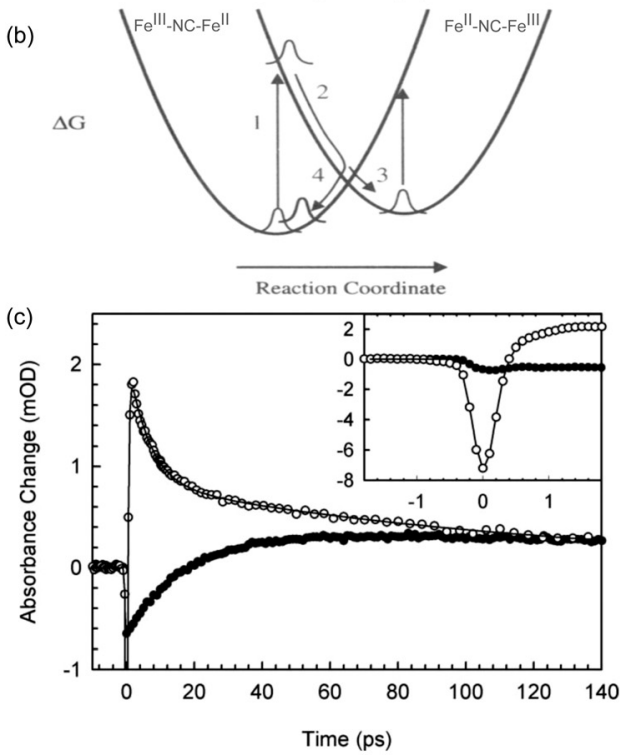

Fig. 3 Ultrafast dynamics in Fe-Fe PB. (a) The early 50 fs dynamics in the polarisation dependent transient transmission of FeFe PB shows a difference between the parallel $\left(S_{\|}\right)$and perpendicular $\left(S_{\perp}\right)$ signals. (b) Model developed by Arnett et al. showing how either the excited CT state (2) can decay back to the groundstate $(4 \rightarrow 1)$ or how a long-lived CT state (3) could be formed. (a) and (b) are reprinted with permission from Arnett et al. J. Am. Chem. Soc., 1995, 117, 12262-12272. ${ }^{122}$ Copyright 1995 American Chemical Society. (c) In an experiment by Weidiner et al., ESA probed at $800 \mathrm{~nm}$ was identified after pumping at both $800 \mathrm{~nm}$ (open circles) and IR pulses resonant with the $\mathrm{CN}$ stretch mode (solid circles). After an initial bleach signal, the IR-pumped signal shows an ESA (positive signal). Figure reprinted from Weidiner et al. J. Chem. Phys., 2011, 134, 124510, ${ }^{127}$ with the permission of AIP Publishing.

there is no change in the number of dipole-allowed transitions in this direction. Wavelength dependent studies were also carried out and showed a red-shift in the stimulated emission peak supporting that the $15 \mathrm{fs}$ time constant is due to the rapid decay of the excited state.

In the following $50 \mathrm{fs}$, the electron density spreads out between the remaining five $\mathrm{Fe}^{\mathrm{III}}\left(\mathrm{t}_{2 \mathrm{~g}}{ }^{3} \mathrm{e}_{\mathrm{g}}{ }^{2}\right)$ ions, which now have a slight $\mathrm{t}_{2 \mathrm{~g}}{ }^{4} \mathrm{e}_{\mathrm{g}}{ }^{2}$-character. This delocalisation leads to a more isotropic charge distribution. There is a pronounced decrease in the transmittance in the parallel probe beam due to further absorption at the MMCT band (less GSB) that has a transition dipole moment aligned with the beam and an increase in transmission in the perpendicular probe beam (more GSB). This indicates that in the 50 fs timeframe after photoexcitation, the electron is no longer localised on a single ion and is delocalised amongst six $\mathrm{Fe}$ ions surrounding the $\mathrm{Fe}^{\mathrm{III}}$ ion with electron configuration $\mathrm{t}_{2 \mathrm{~g}}{ }^{5} \mathrm{e}_{\mathrm{g}}{ }^{0}$. After around $50 \mathrm{fs}$, the parallel and perpendicular decays are identical, which the authors attribute to the localisation on the photoexcited electron to a single metal ion but with the transition dipole moment of these CT pairs randomly aligned. Fitting the deconvolved data yields a biexponential fit with time constants around 250 and 900 fs.

Recovery of the ground state can be monitored by a decrease in GSB. The authors observed ESA in the wavelength-resolved studies. This was attributed to the formation of a relaxed self-trapped CT state (Fig. 3b). The authors developed a kinetic model, which gave rate constants for the BET four times $\left(k_{\mathrm{BET}}=3.5 \pm 0.8 \mathrm{ps}^{-1}\right)$ that of the relaxed CT state $k_{\mathrm{CT}}=0.9 \pm 0.2 \mathrm{ps}^{-1}$. Assuming these are the only decay mechanisms available to $\mathrm{PB}$, this suggests a quantum yield of the CT state of around $20 \%$. The residuals of the fits exhibit a damped oscillatory feature suggesting a vibrational component to the decay. A Fourier analysis of the data showed strong oscillatory components at $75 \mathrm{~cm}^{-1}$ (not assigned) and $270 \mathrm{~cm}^{-1}$ (heavy-light-heavy motion of Fe-CN-Fe). ${ }^{126}$ These are on the same order of magnitude as what is found for the solvated RuRu and RuFe dimers discussed in Section 2 (170, 270, and $\left.488 \mathrm{~cm}^{-1}\right)$. As expected, excitation of the MMCT results in excitation of vibrational modes, here manifested as a nuclear wavepacket.

The interpretation of a self-trapped state has been questioned by a more recent study by Weidinger et al., making use of time-resolved vibrational and electronic spectroscopies on colloidal PB nanoparticles. ${ }^{127}$ Weidinger et al. performed timeresolved measurements using $800 \mathrm{~nm}$ both as pump and probe, and could reproduce Arnett's work. By exciting with $800 \mathrm{~nm}$ (electronic excitation of the MMCT) and IR probing, they found very fast BET and vibrationally excited PB nanoparticles. From probing with IR, they could conclude that other modes than the CN stretch were populated, and these were assigned to lowfrequency lattice phonons. Excitation of the low-frequency modes was of course also observed by Arnett as vibrational coherences made possible with their short 20 fs temporal resolution (which Weidinger did not have access to). Interestingly, Weidinger et al. found very similar results in the $800 \mathrm{~nm}$ probe, when exciting the $\mathrm{CN}$ stretch mode directly. They observed that when probing with $800 \mathrm{~nm}$ after the direct IR pumping, there is an increase in the absorption at $800 \mathrm{~nm}$ (Fig. 3c). Arnett et al. previously assigned this increase in absorption (ESA) to an excited self-trapped CT state. However, because Weidinger had directly excited the $\mathrm{CN}$ stretch instead of an electronic excitation at the MMCT (800 nm), they could conclude that the ESA is a result of vibrational excitation, changing the MMCT transition oscillator strength and that there is no long-lived CT state in the FeFe PB. The anisotropy measurements by Arnett et al. do indicate that within the first 50 fs there is a delocalisation of the MMCT state but Weidingers measurements, albeit with a poorer temporal resolution, indicate that instead of a trapped CT state, a vibrationally hot ground state is formed. However, the timescales are rather different, and a broadband TA measurement might shed more light on the problem. Nevertheless, it is clear that heating of the lattice is important and similar signature of ESA due to vibrational heating has been observed in thin films of hematite $\left(\alpha-\mathrm{Fe}_{2} \mathrm{O}_{3}\right){ }^{128}$ Clearly it is advantageous to probe the dynamics 
using a range of different techniques that are sensitive to different aspects of the complex photoinduced processes in PBAs.

\subsection{Co-Fe PBA}

One of the most fascinating PBAs is the Co-Fe PBA because it is photomagnetic. The first observation was made by Sato et al., who found that shining light on $\mathrm{K}_{0.2} \mathrm{Co}_{1.4}\left[\mathrm{Fe}(\mathrm{CN})_{6}\right] \cdot 6.9 \mathrm{H}_{2} \mathrm{O}$ results in an increase in the sample magnetisation. ${ }^{115}$ Key material parameters were quickly identified after the initial discovery and it was shown that by inserting positive counter ions into the lattice, such as $\mathrm{Rb}^{+}$and $\mathrm{Na}^{+}$, the Co-Fe PBA could be switched from a diamagnet to ferrimagnet using light (Fig. 4). ${ }^{79,80,129}$ There are two phases in this PBA. In the lowtemperature (LT) phase, the oxidation states are $\mathrm{Co}^{\mathrm{III}}$ and $\mathrm{Fe}^{\mathrm{II}}$, both with $S=0$ (Fig. 4a). The high-temperature (HT) phase comprises $\mathrm{Co}^{\mathrm{II}}(S=3 / 2)$ and $\mathrm{Fe}^{\mathrm{III}}(S=1 / 2)$ (Fig. 4b). Upon photoexcitation of the LT phase at $c a .540 \mathrm{~nm}$, a CT state is formed, together with a spin-rearrangement on the $\mathrm{Co}^{\mathrm{II}}$ site, resulting in the HT phase. The possibility to switch a diamagnet to a ferrimagnet is a very exciting prospect and is not observed in more conventional magnetic materials. The magnetic order in the photoexcited state arises because of the superexchange interaction between the spin centres, mediated via the charged bridging cyanide ligand. There is therefore a large on-going
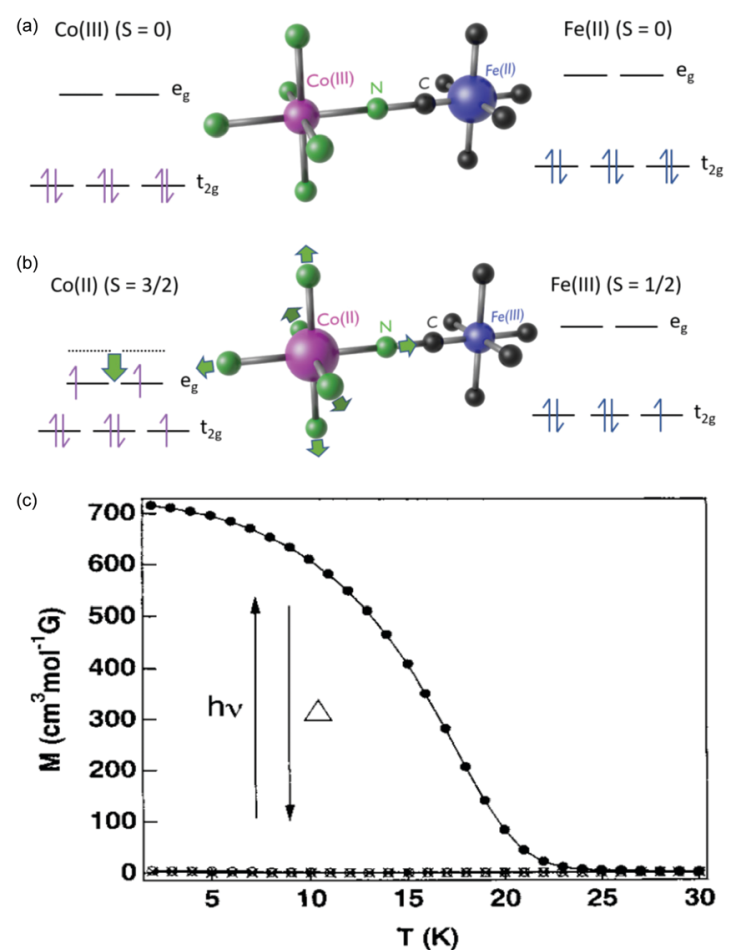

Fig. 4 Electronic structure of the Co-Fe PBA in (a) the low-temperature $(\mathrm{LT})$ and (b) high-temperature (HT) phases. (c) Magnetisation curves before (open circles) and after (solid circles) illumination from a Hg-Xe lamp of $\mathrm{Rb}_{0.66} \mathrm{CO}_{1.25}\left[\mathrm{Fe}(\mathrm{CN})_{6}\right] \cdot 4 \cdot 3 \mathrm{H}_{2} \mathrm{O}$. Data points marked with crosses were recorded after thermal treatment at $150 \mathrm{~K}$, overlapping with the magnetisation before illumination. Figure (c) reprinted with permission from Sato et al. Inorg. Chem., 1999, 38, 4405. ${ }^{79}$ Copyright 2021 American Chemical Society. effort to understand the underlying processes and one important question that remains unsolved is how fast the magnetic longrange order arises.

One of the first ultrafast studies was carried out by Kamioka et al. on $\mathrm{Co}^{\mathrm{II}}\left[\mathrm{Fe}^{\mathrm{III}}(\mathrm{CN})_{6}\right]_{2 / 3} \cdot 5 \mathrm{H}_{2} \mathrm{O}$, which is found in the HT phase down to very low temperatures and is ferrimagnetic below $14 \mathrm{~K}^{130}$ The team employed transient absorption spectroscopy to observe the formation and lifetime of a CT state after excitation at the red-edge of the MMCT $(800 \mathrm{~nm})$ and LMCT $(400 \mathrm{~nm})$ bands in $10 \mathrm{~nm}$ diameter particles in Nafion 117 cavities. In both excitation cases, GSB and ESA were observed at wavelengths below $550 \mathrm{~nm}$ and above $700 \mathrm{~nm}$, respectively. The results were interpreted as the formation of a CT state and they could describe the subsequent decay using a biexponential model consisting of a fast $\left(\tau_{\text {fast }}\right)$ and slow $\left(\tau_{\text {slow }}\right)$ component in each excitation condition with prefactors $A_{\text {fast }}$ and $A_{\text {slow }}$ (Fig. 5). The time constants for the biexponential fits were $\tau_{\text {fast }}=20-30$ ps and $\tau_{\text {slow }}=100-300 \mathrm{ps}$. $\tau_{\text {fast }}$ was ascribed to the decay of the Franck-Condon CT state i.e. without local

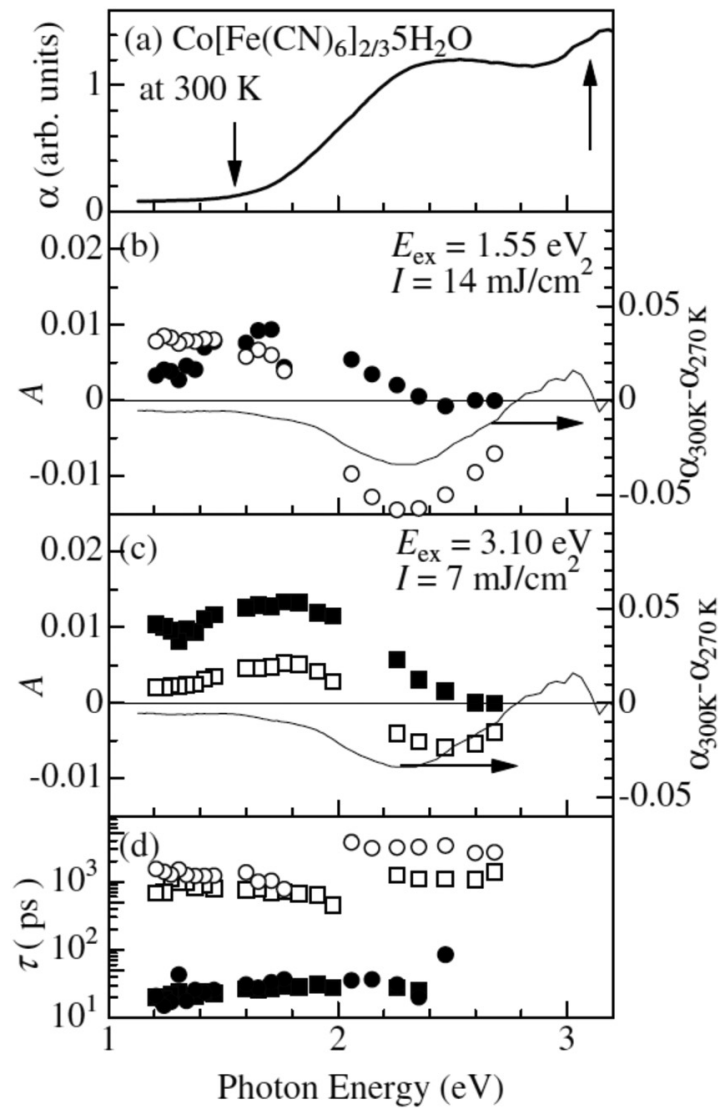

Fig. 5 Ultrafast dynamics in Co"l[Fe"ll $\left.(\mathrm{CN})_{6}\right]_{2 / 3} \cdot 5 \mathrm{H}_{2} \mathrm{O}$ probed by TA spectroscopy. The static absorption spectrum is shown in (a) and the arrows indicate the two excitation wavelengths. The amplitudes $A$ from biexponential fits are shown in (b) and (c), where filled symbols correspond to the fast time constant and open symbols to the slow constant. The actual time constants (fast and slow) are shown in (d). The thin lines in (b) and (c) are differential (static) absorption spectra at different temperatures. Reprinted figure with permission from Kamioka et al. Phys. Rev. B, 2008, 77, 180301(R). ${ }^{130}$ Copyright 2021 by the American Physical Society. 
lattice relaxation. Although $A_{\text {fast }}$ is roughly constant between the two excitation conditions, $A_{\text {slow }}$ is enhanced dramatically by the MMCT over the LMCT and it was suggested that the slow component is due to self-trapped CT states with lattice distortion. The authors argue that LMCT is less likely to create a selftrapped CT state as two charge transfers must occur: the photoinduced LMCT then a MLCT from the $\mathrm{Co}^{\mathrm{II}}$ to the $\mathrm{CN}^{-}$. The GSB is due to the decline in the number of $\mathrm{Co}^{\mathrm{II}}-\mathrm{Fe}^{\mathrm{III}}$ pairs and the ESA is likely from excited spin states in $\mathrm{Co}^{\mathrm{III}}$ with high spin $\left(\mathrm{t}_{2 \mathrm{~g}}{ }^{4} \mathrm{e}_{\mathrm{g}}{ }^{2}\right)$ and intermediate $\left(\mathrm{t}_{2 \mathrm{~g}}{ }^{5} \mathrm{e}_{\mathrm{g}}{ }^{1}\right)$ configurations. The lifetime of the CT states increases with increasing pump fluence and they observed lifetimes from 2 ns at low fluence to $6 \mathrm{~ns}$ at high fluence. At low fluence, a lower density of CT pairs will be created and, therefore, the 2 ns lifetime is associated with isolated CT pairs. At high fluence, a higher density of CT pairs will be formed that manifest into a chargeordered cluster stabilising the photoexcited state.

Moritomo et al. used time-resolved X-ray absorption finestructure (XAFS) spectroscopy and optical transmittance to study $\mathrm{Na}_{0.8} \mathrm{Co}^{\mathrm{II}}\left[\mathrm{Fe}^{\mathrm{II}}(\mathrm{CN})_{6}\right]_{0.90} \cdot 2.9 \mathrm{H}_{2} \mathrm{O}$ at $300 \mathrm{~K}^{131,132}$ This PBA is in the LT phase up to $500 \mathrm{~K}$ unlike the $\mathrm{Co}^{\mathrm{II}}-\mathrm{Fe}^{\mathrm{III}}$ PBA previously discussed. The sample was excited with 130 fs $800 \mathrm{~nm}$ laser pulses. The XAFS measurements showed that a CT state with high-spin $\mathrm{Co}^{\mathrm{II}}$ is formed within the time-resolution of the measurement (100 ps). The CT state decayed with a lifetime of $32 \mathrm{~ns}$ at room temperature. The photoexcitation causes an expansion of the lattice parameters by $0.1 \%$ because of population of anti-bonding $\mathrm{e}_{\mathrm{g}}$ orbitals in the high-spin $\mathrm{Co}^{\mathrm{II}}$ state. This expansion decays on a time frame of about $40 \mathrm{~ns}$ correlating with the lifetime of the CT state measured by optical pump-probe measurements carried out simultaneously with the X-ray measurements. The lattice then begins to expand again after $100 \mathrm{~ns}$ due to heating effects.

In a different study, Zerdane et al. used X-ray absorption near edge structure (XANES) to study CsCoFe PBA $\left(\mathrm{Co}^{\mathrm{III}}(S=0)-\right.$ $\left.\mathrm{Fe}^{\mathrm{II}}(S=0)\right) .{ }^{133}$ They found that starting in the low-spin configuration at room temperature and exciting with $650 \mathrm{~nm}$ light, the XANES data clearly showed the transfer of an electron from $\mathrm{Fe}^{\mathrm{II}}$ to $\mathrm{Co}^{\mathrm{III}}$ and that $\mathrm{Co}^{\mathrm{II}}$ was formed in the high-spin state. The XANES data also indicated that the geometry around the Co site is changed as a result of the spin crossover. The dynamics was limited to the $100 \mathrm{ps}$ time resolution in the experiment. Complementary optical pump-probe measurements showed that the CT state has a lifetime on the order of a few microseconds at room-temperature.

These first time-resolved measurements at synchrotrons enables studies with higher temporal resolution at XFEL facilities. This was recently done by Cammarata $e t$ al. who used both XANES and extended XAFS (EXAFS) at the LCLS XFEL with a 25 fs temporal resolution. ${ }^{121}$ The sample studied was a colloidal solution of $\mathrm{Cs}_{0.7} \mathrm{Co}\left[\mathrm{Fe}(\mathrm{CN})_{6}\right]_{0.9}$ nanoparticles with $11 \mathrm{~nm}$ diameter in the LT phase at room temperature. ${ }^{134}$ This was a ground-breaking study in many ways because it determined the nature of the transition at $540 \mathrm{~nm}$, for which there was previously some debate, ${ }^{119,120}$ and could even show the sequence of the initial states involved in the CT and spin transitions. The time-resolved data at the Co K-edge

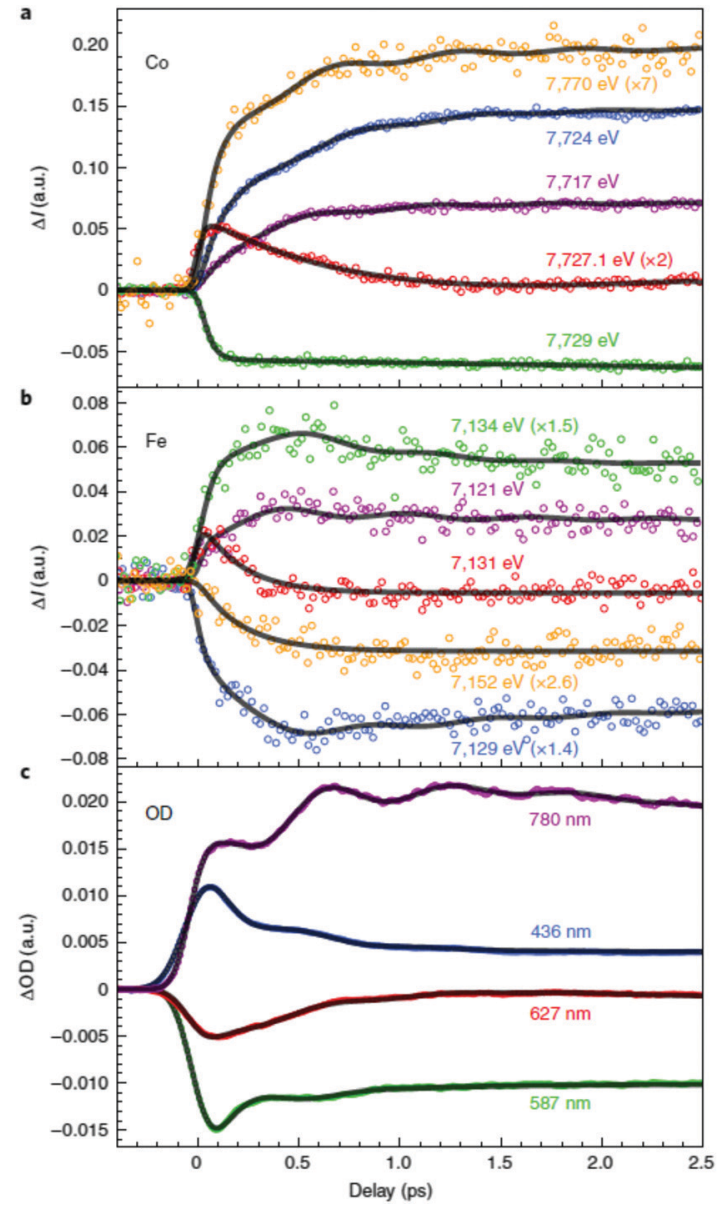

Fig. 6 Time-resolved X-ray absorption data of a colloidal solution of $\mathrm{Cs}_{0.7} \mathrm{Co}\left[\mathrm{Fe}(\mathrm{CN})_{6}\right]_{0.9}$ nanoparticles obtained using the LCLS X-ray freeelectron laser (XFEL) at the (a) Co and (b) Fe K-edges. ${ }^{121}$ The data show that the initial dynamics takes place on the Co site after photoexcitation, which followed by a charge-transfer from Co to Fe. The change in $e_{g}$ population leads to rapid expansion of the $\mathrm{Co}-\mathrm{N}$ bonds and the launch of lattice torsional modes. This is more clearly seen as oscillations in the optical TA measurements shown in (c). Reprinted by permission from Springer Nature: Nature Chemistry Charge transfer driven by ultrafast spin transition in a CoFe Prussian blue analogue, Marco Cammarata et al. Copyright 2021.

had to be fitted with three decay constants of 50, 200 and 450 fs (Fig. 6). Interestingly, the Fe edge only showed the 200 and 450 fs components, suggesting that the initial dynamics takes place on the Co site. This observation therefore determined that the $540 \mathrm{~nm}$ transition corresponds to a d-d transition on the $\mathrm{Co}^{\mathrm{III}}$ site, which was also confirmed by time-dependent density functional theory (TD-DFT) calculations. The transition involves populating antibonding $\mathrm{e}_{\mathrm{g}}$ orbitals and there is therefore a rapid expansion of the Co- $\mathrm{N}$ bonds. This in turn reduces the energy difference between the $t_{2 g}$ and $e_{g}$ orbitals and the high-spin state is formed, which could be seen in the EXAFS signal. The XANES signal on the other hand, shows that the CT takes place within $200 \mathrm{fs}$, as large shifts in both the Co and Fe K-edges are observed corresponding to a change in oxidation state. The authors therefore concluded that it was the spin transition that drives the CT. Temporal oscillations are 
also observed in the data corresponding to a lattice torsional mode at $1.65 \mathrm{THz}\left(55 \mathrm{~cm}^{-1}\right)$. The authors suggest that the breathing mode of the Co expansion, predicted to occur at $11.2 \mathrm{THz}$ $\left(374 \mathrm{~cm}^{-1}\right)$, is not observed because the lattice has no time to expand on this short timescale for which the initial expansion takes place (half the period of the breathing mode). We note that the FeFe study by Arnett mentioned above, ${ }^{122}$ identified oscillations in their data corresponding to 75 and $270 \mathrm{~cm}^{-1}$. Presumably these are similar modes to what was observed in the CoFe PBA. Arnett did not mention any counterions and it is therefore possible that the mode at $270 \mathrm{~cm}^{-1}$ was observed because of vacancies in the lattice, in contrast to the CoFe studied by Cammarata, which have fewer vacancies. Furthermore, there is no change in spin in the FeFe PB, whereas the torsional modes might be critical for the ultrafast ISC in CoFe to take place, similarly to the strain waves launched during ultrafast demagnetisation of Fe films. ${ }^{56}$ Recent X-ray diffuse scattering studies of single-crystal of various PBAs revealed a range of different types of vacancies, ${ }^{135}$ which could be a promising route to steer the dynamics in the excited state.

There have also been several computational studies to understand the dynamics of the CoFe PBA. Recently, van Veenendaal employed a dissipative quantum mechanical model where the cobalt ion is coupled to the damped breathing mode of the $\mathrm{Co}^{\mathrm{II}}-\mathrm{CN}$ bonds. ${ }^{119}$ The simulation begins after photoexcitation with a Franck-Condon ${ }^{2} \mathrm{E}$ state, centred on the $\mathrm{Co}^{\mathrm{II}}$ with electron configuration $\mathrm{t}_{2 \mathrm{~g}}{ }^{6} \mathrm{e}_{\mathrm{g}}{ }^{1}$. This assumes that a CT from $\mathrm{Fe}$ to Co takes place first. However, the recent XFEL measurement by Cammarata et al. show that the spin transition occurs first as discussed above. However, the work by van Veenendaal is very important and gives many insights into the interplay between electronic and nuclear degrees of freedom, as well as highlights the complex multi-electron correlation effects taking place. Within 20 fs the wavepacket undergoes ISC to the ${ }^{4} \mathrm{~T}_{1}$ state $\left(\mathrm{t}_{2 g}{ }^{5} \mathrm{e}_{\mathrm{g}}{ }^{2}\right)$, corresponding to a change in spin state from $S=1 / 2$ to $90 \%$ of the expected value $S=3 / 2$. The dynamics of the doublet to quartet transition are only weakly dependent on damping to vibrational modes. After the initial $20 \mathrm{fs}$, the conversion to the $S=3 / 2$ state is heavily dependent on the damping due to the involvement of other quartet states, highlighting that multi-electron correlation effects and their coupling to nuclear degrees of freedom are important. It was observed that the value of the spin-orbit interaction oscillates during the first $300 \mathrm{fs}$ and played a role in the ISC process. van Veenendaal predicts that time-resolved X-ray absorption measurements at XFELs should enable the direct observation of the change in spin-orbit interaction during the early dynamics, ${ }^{119,136}$ which is a very exciting possibility.

\subsection{Mn-Fe PBA}

Another interesting photomagnetic system is the $\mathrm{Rb}_{x} \mathrm{Mn}$ $\left[\mathrm{Fe}(\mathrm{CN})_{6}\right]_{(x+2) / 3} \cdot z \mathrm{H}_{2} \mathrm{O}$ PBA. It has been shown that this PBA can be controlled by external stimuli and a single laser shot can cause demagnetisation. ${ }^{137-140}$ This compound is characterised by a LT phase $\mathrm{Fe}^{\mathrm{II}}(S=0)-\mathrm{CN}-\mathrm{Mn}^{\mathrm{III}}(S=2)$ and a HT phase, where an electron has been transferred from Fe to Mn, yielding
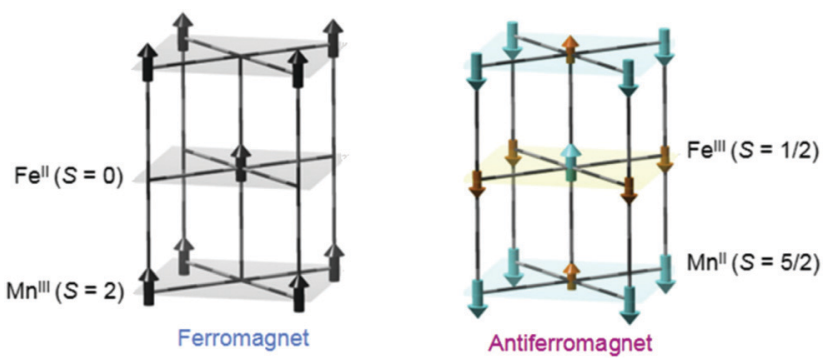

Fig. 7 Magnetic ordering of the MnFe PBA in the low-temperature (left) and photoinduced high-temperature phases (right). Reprinted with permission from Tokoro et al. Chem. Mater., 2008, 20, 423-428. ${ }^{142}$ Copyright 2021 American Chemical Society.

$\mathrm{Fe}^{\mathrm{III}}(S=1 / 2)-\mathrm{CN}-\mathrm{Mn}^{\mathrm{II}}(S=5 / 2) \cdot{ }^{138}$ This bistability is seen as a thermal phase transition with a wide loop (bistability characterised by thermal hysteresis in the magnetic susceptibility) and attributed to the flexibility afforded by the cyano-bridges, allowing for a Jahn-Teller distortion to take place at low temperatures $\left(\mathrm{Mn}^{\mathrm{III}}\right.$ is Jahn-Teller distorted). The $\mathrm{RbMnFe}$ PBA has a broad absorption around 400-600 nm, consisting of both $\mathrm{Mn}^{\mathrm{III}} \mathrm{d}-\mathrm{d}$ transitions and an intervalence transition from $\mathrm{Fe}^{\mathrm{II}}$ to $\mathrm{Mn}^{\mathrm{III}} \cdot{ }^{140,141}$ The photoinduced HT phase (PIHT) can be reached by optical excitation of the magnetically ordered LT phase at $3 \mathrm{~K}$ (ferromagnetic ordering of the $\mathrm{Mn}^{\mathrm{III}}$ spins), which causes a demagnetisation of the sample. ${ }^{137}$ This is because the conversion from $S=0$ to $S=1 / 2$ on the Fe ions, which leads to an overall antiferromagnetic long-range magnetic order in the PIHT phase (Fig. 7). Vibrational spectroscopy ${ }^{142-144}$ and X-ray diffraction ${ }^{140}$ demonstrate that the HT phase has formed in the photoexcited state. Tokoro et al. found that laser fluences higher than $9 \mathrm{~mJ} \mathrm{~cm}^{-2}$ are needed to observe the photoinduced demagnetisation. ${ }^{137}$ Just as in the case for Co$\mathrm{Fe}$, this indicates that there is a need to form the necessary number of switched sites in the crystal for a phase-transition to occur. Despite the large laser fluence, the LT is recovered after annealing at $150 \mathrm{~K}$. Interestingly, the LT phase can also be recovered by further optical excitation and the magnetisation grows correspondingly. This presents an interesting way to optically switch the magnetisation in this PBA using a reversible process. Asahara et al. have studied time-resolved IR measurements and found that the charge-transfer occurs within their temporal resolution (decrease of the LT phase within $<1 \mathrm{ps}$ ), but that the signal is dominated by the boundaries between the LT and PIHT phases (Fig. 8). ${ }^{102}$ The authors concluded that relatively small domains and/or fjord-like domains are formed shortly after the excitation pulse. Zerdane $e t$ al. performed timeresolved XANES on the RbMnFe PBA with a 100 ps time resolution. ${ }^{133}$ They found evidence that the MMCT excitation produces a change in oxidation states and complementary optical pump-probe measurements showed that this state has a lifetime on the order of $10 \mathrm{~ms}$ at $140 \mathrm{~K}$.

A computational investigation on how the delocalised molecular orbitals across the $\mathrm{Fe}-\mathrm{CN}-\mathrm{Mn}$ bond depends on the low-frequency transverse modes (around $300-500 \mathrm{~cm}^{-1}$ ) have been carried out by 
(a)

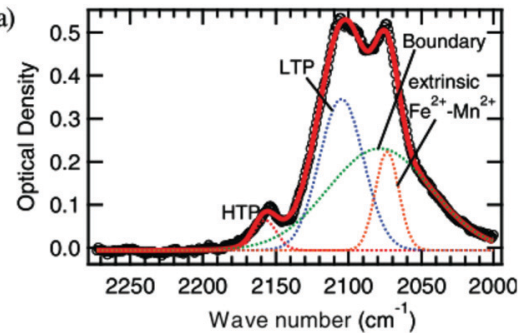

(b)

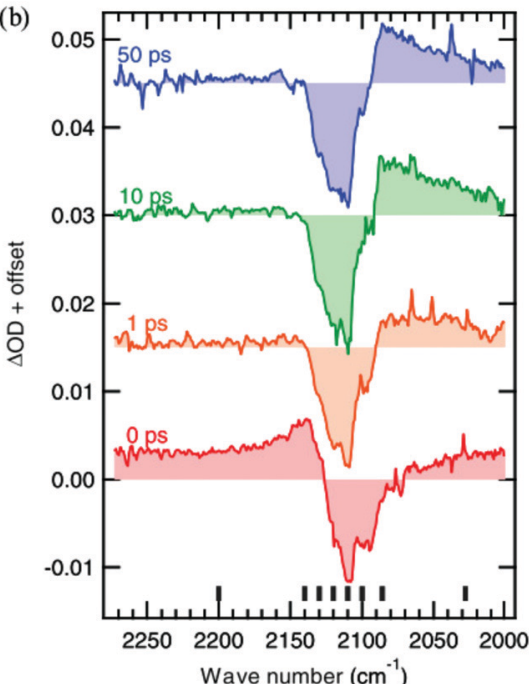

Fig. 8 Vibrational spectroscopy of the $\mathrm{Mn}-\mathrm{Fe}$ PBA at $4 \mathrm{~K}$. The static absorption spectrum is shown in (a) where the low-temperature (LT) and photoinduced high-temperature (PIHT) phases can be seen. The sites between the two phases at the boundaries give rise to additional peaks. (b) Time-resolved IR spectra at the cyanide stretch region at selected time delays, showing the transition from the LT phase to the PIHT phase. The signal is dominated by the boundary sites at lower wavenumbers below the bleach of the LT phase $\left(2110 \mathrm{~cm}^{-1}\right)$. Reprinted figure with permission from Asahara et al. Phys. Rev. B, 2012, 86, 195138. ${ }^{102}$ Copyright 2021 by the American Physical Society.

Tokoro et al. ${ }^{139,145}$ As the bond angle changes, the calculations indicate a CT from $\mathrm{Fe}^{\mathrm{II}}-\mathrm{CN}-\mathrm{Mn}^{\mathrm{III}}$ to $\mathrm{Fe}^{\mathrm{III}}-\mathrm{CN}-\mathrm{Mn}^{\mathrm{II}}$. Clearly the coupling to vibrational modes/phonons is important for mediating the CT-induced phase-transition, as has been seen in other PBAs discussed above.

\subsection{V-Cr PBA}

The $\mathrm{V}^{\mathrm{II} / \mathrm{III}}-\mathrm{Cr}^{\mathrm{III}}$ PBA is one of the very few room-temperature molecule-based magnets. ${ }^{69}$ It is brightly blue-coloured due to intense MMCT at 540 and $660 \mathrm{~nm}$ (wavelength depends on the vanadium oxidation state). ${ }^{88,118,146,147}$ Bozdag et al. found reversible photo-induced changes to the magnetisation of a sample of $\mathrm{K}_{1.54} \mathrm{~V}^{\mathrm{II}}{ }_{0.77} \mathrm{~V}^{\mathrm{III}}{ }_{0.08}\left[\mathrm{Cr}^{\mathrm{III}}(\mathrm{CN})_{6}\right]\left(\mathrm{SO}_{4}\right)_{0.16}{ }^{148}$ The sample was placed in a magnetic field of 10 Oe and when irradiation with $350 \mathrm{~nm}$ CW laser light at the LMCT band, a decrease in the magnetisation of around $0.5 \%$ was observed. At a temperature of $10 \mathrm{~K}$, this change in magnetisation stayed constant until irradiated with $514 \mathrm{~nm}$ light, when the magnetisation partially recovered. The authors also found that the magnetisation fully recovers when heating the sample above $250 \mathrm{~K}$. Bozdag et al. attributed the decreasing magnetisation to the LMCT inducing structural distortions in the metal-ligand bond and/or changes in magnetic anisotropy.

The MMCT transitions in the visible spectrum give rise to a relatively large magneto-optical (MO) signal in thin films fabricated using electrodeposition on transparent substrates. ${ }^{84,88}$ Ohkoshi et al. showed that the MO signal from the MMCT is proportional to the sample magnetisation. ${ }^{88}$ This opens possibilities to do time-resolved Faraday rotation measurements. The first fs spin-state sensitive investigation of a PBA was carried out by Johansson $e t$ al. using ultrafast time-resolved Faraday rotation and TA on the V-Cr PBA. ${ }^{147}$ The authors found a large GSB of the MMCT transitions after exciting the red edge of the LMCT band at $400 \mathrm{~nm}$. The optical assignments were supported by TD-DFT calculations on the $\mathrm{V}-\mathrm{Cr}$ molecular unit. The signal decayed and reached a plateau within a few ps. In a later TA study with improved time-resolution, ${ }^{149}$ it was shown that the GSB decayed with $c a .200$ fs and 1 ps time constants to the plateau, which stayed constant for over 2 ns.

In the femtosecond magneto-optical (fs-MO) measurements, ${ }^{147}$ a white-light continuum spanning $480-690 \mathrm{~nm}$ was used to monitor the changes in transmission and the MO signal (Faraday

(a)

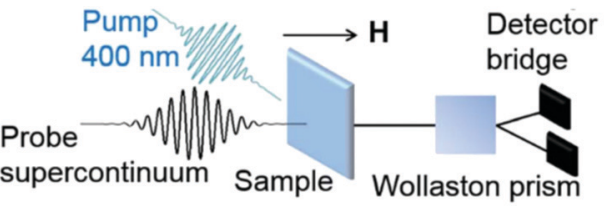

(b)

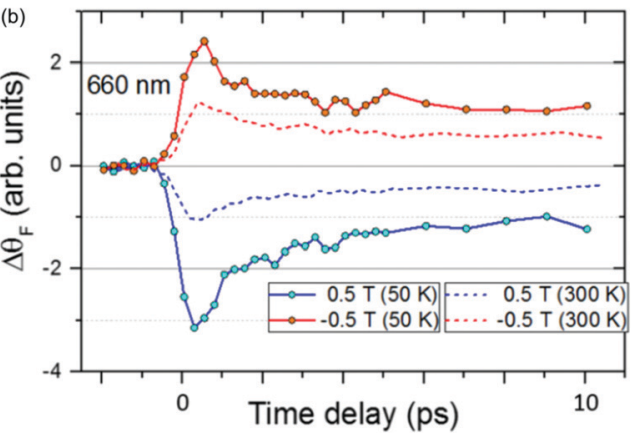

(c) Super-exchange

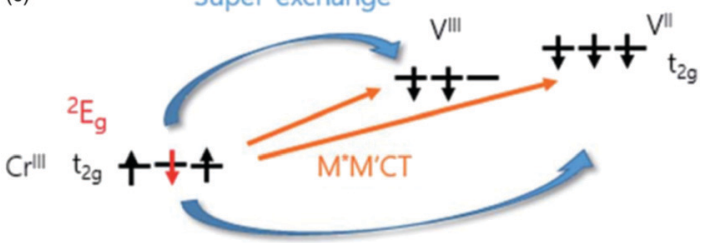

Fig. 9 Ultrafast spin dynamics in the $\mathrm{V}-\mathrm{Cr}$ PBA. ${ }^{147}$ (a) Experimental setup used to measure the fs magneto-optical ( $f s-M O$ ) signal. A small wavelength range of the white-light continuum is selected as a probe and transmitted through the sample. The change in polarisation direction (Faraday rotation, $\Delta \theta_{\mathrm{F}}$ ) is measured using a Wollaston prism and a bridged photodiode pair. (b) The signal at a probe wavelength of $660 \mathrm{~nm}$ measured as a function of time delay between the probe and $400 \mathrm{~nm}$ pump. The external magnetic field is either aligned parallel or antiparallel with the laser propagation direction. (c) The photoinduced spin-flip on the $\mathrm{Cr}$ sites results in a rapid change in the superexchange interaction and the fsMO signal. 
rotation and ellipticity) was measured as a function of time delay between the pump and probe pulses. Measurements were carried out at 50 and $300 \mathrm{~K}$ and in $\pm 0.5 \mathrm{~T}$ external magnetic fields in order to separate the optical and magnetic dynamical response. The fs-MO signal showed a very fast, sub-ps, response following the TA timescales, as seen in Fig. 9. This fast response is different to what is typically observed in magnetic dielectrics, where the spin-phonon interaction take place on a much longer timescale (100s of ps). ${ }^{150-154}$ For this fast fs-MO signal, the local change in spin populations shows up at short times in the signal.

It is known that the local spin-configuration on $\mathrm{Cr}^{\mathrm{III}}$ sites in the ground state gives $S=3 / 2$ and that the first excited state corresponds to one of the electrons flipped, which in a local picture corresponds to $S=1 / 2$. In molecules ${ }^{5,155}$ and solids ${ }^{156,157}$ this state can be populated within a few 100 fs. Johansson et al. interpreted the fast change in fs-MO signal as due to local spinflips on the Cr sites after photoexcitation, which in turn will affect the superexchange interaction. The ps decay is due to heating of the lattice, similarly to other PBAs. The dynamics of the reaction are summarised in Fig. 9 along with the timeresolved MO signal. This work has shown the possibility of using ultrafast MO to directly measure spin dynamics and changes in the superexchange interaction. However, long-lived CT states could also play a role and future element-specific measurements, using for example XFELs, could shed more light on the problem.

\section{Summary and outlook}

Light-induced spin flips can happen on sub-100 fs timescales in systems ranging in size from molecules to magnetically ordered metals and dielectrics. Connecting them is that there is strong coupling between electronic, nuclear and spin degrees of freedom. We argue that molecule-based magnets, such as PBAs, bridge the limits between individual molecules and long-range ordered materials, and provide the best of both worlds with the advantage of possibilities for high-level calculations based on the dimers of the molecular building blocks.

Much can be learned from studying cyano-bridged dimers and comparing these results to PBAs. It is clear that excitation of vibrational/phonon modes take place on the sub-ps timescale in both the dimers and most of the PBAs. TA and XFEL measurements show that in some PBAs long-lived CT states are formed, which eventually can lead to a change in the long-range magnetic order, as in the Co-Fe PBA. In these measurements, one also observes a launch of coherent phonons, such as lattice bending modes, which is particularly important when the population of antibonding $\mathrm{e}_{\mathrm{g}}$ orbitals are changed. It will be interesting to conduct experiments using a $\mathrm{THz}$ pump to directly excite these phonon modes. The pioneering work by Cammarata et al. highlighted the power of XFEL measurements with element-specificity, which enabled the team to demonstrate that a spin-flip occurs before the charge-transfer in the Co-Fe PBA. ${ }^{121}$ It is known that vacancies and the exact stoichiometry can have a large effect on the final photomagnetic
State because these parameters influence the lattice rigidity. ${ }^{79,80,129}$ Currently, there is a lack of systematic ultrafast studies comparing the dynamics in PBAs that only differ in their stoichiometric ratios. Work on the V-Cr PBA, using magneto-optical methods for the first time, could show that it is possible to change the magnetic exchange between sites in the lattice on a sub-picosecond timescale. ${ }^{147}$ This technique is promising in combination with XFEL measurements to understand ultrafast photoinduced magnetisation dynamics. We note that steady-state illumination of the photomagnetic Co-Fe PBA results in an increase in the $\mathrm{MO}$ signal, ${ }^{89}$ which would be interesting to study in a time-resolved experiment.

Until now, the electron dynamics have been explained using a localised picture of the wavepacket and focusing on direct chargetransfer between localised sites. It has been shown that optical excitation does lead to long-range structural ordering, as in the MnFe PBA, and rapid heating of the lattice. The question then is if one should also consider a delocalised conduction band in the more crystalline PBAs to see if the dynamics can be described using methods from condensed matter physics. For example, spin and charge dynamics in lead halide perovskites are described well using a band theory picture. Exciting electrons into the conduction band, Giovanni et al. were able to measure spin relaxation times of electrons and holes using time-resolved Faraday rotation, ${ }^{158}$ similarly to what was previously done on Mn-doped semiconductors described in the Introduction. ${ }^{41}$ Likewise, the early 20 fs anisotropy measurements by Arnett et al. pointed to a rapid delocalisation of the charge-transfer state, ${ }^{122}$ which is also seen in molecular $\left[\mathrm{Ru}(\mathrm{bpy})_{3}\right]^{2+},{ }^{125}$ which is a problem that has been discussed for a long time. The question then arises if there is a role for free carriers but very limited amount of work on photoconductivity of PB has been done. ${ }^{159,160}$ Such questions could potentially be answered using terahertz spectroscopy.

It will also be interesting to make use of the elemental specificity of XFELs to explore charge-transfer effects in multilayers of PBAs, such as multicore CoFe PBA. ${ }^{81,161}$ It is possible that time-resolved IR measurements monitoring the different $\mathrm{CN}^{-}$ stretch modes, which provide a spectral fingerprint of the PBA oxidation state, could be used to achieve layer-specific sensitivity. Controlling magnetic (and other) properties in stimuli-responsive and multifunctional devices with fs pulses is an exciting prospect.

The fundamental understanding of manipulating spins with fs laser pulses in PBAs will set the scene to explore other magnetic materials. For example, a molecule-based magnet incorporating chromium ions and pyrazine building blocks was recently made, which displayed ordering temperatures up to $242{ }^{\circ} \mathrm{C}^{162}$ New single-molecule magnets are also being developed that are magnetic around $77 \mathrm{~K} .{ }^{163-165}$ Understanding the fundamental photoinduced processes in magnetic molecules can lead to a change in how fast and efficient we can store digital information in the future.

\section{Conflicts of interest}

There are no conflicts to declare. 


\section{Acknowledgements}

The authors acknowledge support from EPSRC grant EP/S018824/1.

\section{Notes and references}

1 J. K. McCusker, Acc. Chem. Res., 2003, 36, 876-887.

2 E. A. Juban, A. L. Smeigh, J. E. Monat and J. K. McCusker, Coord. Chem. Rev., 2006, 250, 1783-1791.

3 M. Chergui, Acc. Chem. Res., 2015, 48, 801-808.

4 N. H. Damrauer, G. Cerullo, A. Yeh, T. R. Boussie, C. V. Shank and J. K. McCusker, Science, 1997, 275, 54-57.

5 E. A. Juban and J. K. McCusker, J. Am. Chem. Soc., 2005, 127, 6857-6865.

6 J. E. Monat and J. K. McCusker, J. Am. Chem. Soc., 2000, 122, 4092-4097.

7 G. Auböck and M. Chergui, Nat. Chem., 2015, 7, 629-633.

8 H. T. Lemke, K. S. Kjær, R. Hartsock, T. B. van Driel, M. Chollet, J. M. Glownia, S. Song, D. Zhu, E. Pace, S. F. Matar, M. M. Nielsen, M. Benfatto, K. J. Gaffney, E. Collet and M. Cammarata, Nat. Commun., 2017, 8, 15342.

9 W. Zhang, R. Alonso-Mori, U. Bergmann, C. Bressler, M. Chollet, A. Galler, W. Gawelda, R. G. Hadt, R. W. Hartsock, T. Kroll, K. S. Kjær, K. Kubiček, H. T. Lemke, H. W. Liang, D. A. Meyer, M. M. Nielsen, C. Purser, J. S. Robinson, E. I. Solomon, Z. Sun, D. Sokaras, T. B. van Driel, G. Vankó, T.-C. Weng, D. Zhu and K. J. Gaffney, Nature, 2014, 509, 345-348.

10 S. Zerdane, L. Wilbraham, M. Cammarata, O. Iasco, E. Rivière, M. L. Boillot, I. Ciofini and E. Collet, Chem. Sci., 2017, 8, 4978-4986.

11 W. Zhang, K. S. Kjær, R. Alonso-Mori, U. Bergmann, M. Chollet, L. A. Fredin, R. G. Hadt, R. W. Hartsock, T. Harlang, T. Kroll, K. Kubicek, H. T. Lemke, H. W. Liang, Y. Liu, M. M. Nielsen, P. Persson, J. S. Robinson, E. I. Solomon, Z. Sun, D. Sokaras, T. B. van Driel, T. C. Weng, D. Zhu, K. Warnmark, V. Sundstrom and K. J. Gaffney, Chem. Sci., 2017, 8, 515-523.

12 M. Lorenc, J. Hébert, N. Moisan, E. Trzop, M. Servol, M. Buron-Le Cointe, H. Cailleau, M. L. Boillot, E. Pontecorvo, M. Wulff, S. Koshihara and E. Collet, Phys. Rev. Lett., 2009, 103, 028301.

13 E. Collet, N. Moisan, C. Baldé, R. Bertoni, E. Trzop, C. Laulhé, M. Lorenc, M. Servol, H. Cailleau, A. Tissot, M.-L. Boillot, T. Graber, R. Henning, P. Coppens and M. B.-L. Cointe, Phys. Chem. Chem. Phys., 2012, 14, 6192.

14 M. Cammarata, R. Bertoni, M. Lorenc, H. Cailleau, S. Di Matteo, C. Mauriac, S. F. Matar, H. Lemke, M. Chollet, S. Ravy, C. Laulhé, J.-F. Létard and E. Collet, Phys. Rev. Lett., 2014, 113, 227402.

15 K. Kunnus, M. Vacher, T. C. B. Harlang, K. S. Kjær, K. Haldrup, E. Biasin, T. B. van Driel, M. Papai, P. Chabera, Y. Liu, H. Tatsuno, C. Timm, E. Kallman, M. Delcey, R. W. Hartsock, M. E. Reinhard, S. Koroidov, M. G. Laursen, F. B. Hansen, P. Vester, M. Christensen, L. Sandberg, Z. Nemeth, D. S. Szemes, E. Bajnoczi,
R. Alonso-Mori, J. M. Glownia, S. Nelson, M. Sikorski, D. Sokaras, H. T. Lemke, S. E. Canton, K. B. Moller, M. M. Nielsen, G. Vanko, K. Warnmark, V. Sundstrom, P. Persson, M. Lundberg, J. Uhlig and K. J. Gaffney, Nat. Commun., 2020, 11, 634.

16 K. S. Kjær, T. B. Van Driel, T. C. B. Harlang, K. Kunnus, E. Biasin, K. Ledbetter, R. W. Hartsock, M. E. Reinhard, S. Koroidov, L. Li, M. G. Laursen, F. B. Hansen, P. Vester, M. Christensen, K. Haldrup, M. M. Nielsen, A. O. Dohn, M. I. Papai, K. B. Moller, P. Chabera, Y. Liu, H. Tatsuno, C. Timm, M. Jarenmark, J. Uhlig, V. Sundstom, K. Warnmark, P. Persson, Z. Nemeth, D. S. Szemes, E. Bajnoczi, G. Vanko, R. Alonso-Mori, J. M. Glownia, S. Nelson, M. Sikorski, D. Sokaras, S. E. Canton, H. T. Lemke and K. J. Gaffney, Chem. Sci., 2019, 10, 5749-5760.

17 M. Chergui and E. Collet, Chem. Rev., 2017, 117, 1102511065.

18 K. Zhang, R. Ash, G. S. Girolami and J. Vura-Weis, J. Am. Chem. Soc., 2019, 141, 17180-17188.

19 E. S. Ryland, K. Zhang and J. Vura-Weis, J. Phys. Chem. A, 2019, 123, 5214-5222.

20 Y. Jiang, L. C. Liu, H. M. Muller-Werkmeister, C. Lu, D. Zhang, R. L. Field, A. Sarracini, G. Moriena, E. Collet and R. J. D. Miller, Angew. Chem., Int. Ed., 2017, 56, 7130-7134.

21 Y. Jiang, L. C. Liu, A. Sarracini, K. M. Krawczyk, J. S. Wentzell, C. Lu, R. L. Field, S. F. Matar, W. Gawelda, H. M. Müller-Werkmeister and R. J. D. Miller, Nat. Commun., 2020, 11, 1530.

22 C. de Graaf and C. Sousa, Chem. - Eur. J., 2010, 16, 4550-4556.

23 L. A. Fredin, K. Wärnmark, V. Sundström and P. Persson, ChemSusChem, 2016, 9, 667-675.

24 J. Nance, D. N. Bowman, S. Mukherjee, C. T. Kelley and E. Jakubikova, Inorg. Chem., 2015, 54, 11259-11268.

25 M. Abedi, G. Levi, D. B. Zederkof, N. E. Henriksen, M. Pápai and K. B. Møller, Phys. Chem. Chem. Phys., 2019, 21, 4082-4095.

26 M. Pápai, M. Abedi, G. Levi, E. Biasin, M. M. Nielsen and K. B. Møller, J. Phys. Chem. C, 2019, 123, 2056-2065.

27 T. J. Penfold, E. Gindensperger, C. Daniel and C. M. Marian, Chem. Rev., 2018, 118, 6975-7025.

28 C. Daniel, Phys. Chem. Chem. Phys., 2021, 23, 43-58.

29 J. P. Zobel, O. S. Bokareva, P. Zimmer, C. Wolper, M. Bauer and L. Gonzalez, Inorg. Chem., 2020, 59, 14666-14678.

30 P. Chábera, Y. Liu, O. Prakash, E. Thyrhaug, A. E. Nahhas, A. Honarfar, S. Essén, L. A. Fredin, T. C. B. Harlang, K. S. Kjær, K. Handrup, F. Ericson, H. Tatsuno, K. Morgan, J. Schnadt, L. Häggström, T. Ericsson, A. Sobkowiak, S. Lidin, P. Huang, S. Styring, J. Uhlig, J. Bendix, R. Lomoth, V. Sundström, P. Persson and K. Wärnmark, Nature, 2017, 543, 695-699.

31 B. C. Paulus, S. L. Adelman, L. Jamula and J. McCusker, Nature, 2020, 582, 214-218.

32 F. Liedy, J. Eng, R. McNab, R. Inglis, T. J. Penfold, E. K. Brechin and J. O. Johansson, Nat. Chem., 2020, 12, 452-458. 
33 M. A. Naumova, A. Kalinko, J. W. L. Wong, S. Alvarez Gutierrez, J. Meng, M. Liang, M. Abdellah, H. Geng, W. Lin, K. Kubicek, M. Biednov, F. Lima, A. Galler, P. Zalden, S. Checchia, P. A. Mante, J. Zimara, D. Schwarzer, S. Demeshko, V. Murzin, D. Gosztola, M. Jarenmark, J. Zhang, M. Bauer, M. L. Lawson Daku, D. Khakhulin, W. Gawelda, C. Bressler, F. Meyer, K. Zheng and S. E. Canton, J. Chem. Phys., 2020, 152, 214301.

34 R. Bertoni, M. Lorenc, A. Tissot, M. Servol, M. L. Boillot and E. Collet, Angew. Chem., Int. Ed., 2012, 51, 7485-7489.

35 M. Lorenc, C. Balde, W. Kaszub, A. Tissot, N. Moisan, M. Servol, M. Buron-Le Cointe, H. Cailleau, P. Chasle, P. Czarnecki, M. L. Boillot and E. Collet, Phys. Rev. B: Condens. Matter Mater. Phys., 2012, 85, 054302.

36 A. Marino, M. Servol, R. Bertoni, M. Lorenc, C. Mauriac, J. F. Létard and E. Collet, Polyhedron, 2013, 66, 123-128.

37 R. Bertoni, M. Lorenc, T. Graber, R. Henning, K. Moffat, J. F. Letard and E. Collet, CrystEngComm, 2016, 18, 7269-7275.

38 R. Bertoni, M. Lorenc, H. Cailleau, A. Tissot, J. Laisney, M.-L. Boillot, L. Stoleriu, A. Stancu, C. Enachescu and E. Collet, Nat. Mater., 2016, 15, 606-610.

39 A. Marino, M. Cammarata, S. F. Matar, J. F. Létard, G. Chastanet, M. Chollet, J. M. Glownia, H. T. Lemke and E. Collet, Struct. Dyn., 2016, 3, 023605.

40 S. A. Crooker, D. D. Awschalom and N. Samarth, IEEE J. Sel. Top. Quantum Electron., 1995, 1, 1082-1092.

41 S. Crooker, J. Baumberg, F. Flack, N. Samarth and D. D. Awschalom, Phys. Rev. Lett., 1996, 77, 2814-2817.

42 M. Ouyang and D. D. Awschalom, Science, 2003, 301, 1074-1078.

43 D. D. Awschalom, R. Hanson, J. Wrachtrup and B. B. Zhou, Nat. Photonics, 2018, 12, 516-527.

44 A. Kirilyuk, A. V. Kimel and T. Rasing, Rep. Prog. Phys., 2013, 76, 026501.

45 J.-Y. Bigot and M. Vomir, Ann. Phys., 2013, 525, 2-30.

$46 \mathrm{~J}$. Walowski and M. Münzenberg, J. Appl. Phys., 2016, 120, 140901.

47 E. Beaurepaire, J. C. Merle, A. Daunois and J.-Y. Bigot, Phys. Rev. Lett., 1996, 76, 4250-4253.

48 A. Stupakiewicz, K. Szerenos, D. Afanasiev, A. Kirilyuk and A. V. Kimel, Nature, 2017, 542, 71-74.

49 A. Stupakiewicz, K. Szerenos, M. D. Davydova, K. A. Zvezdin, A. K. Zvezdin, A. Kirilyuk and A. V. Kimel, Nat. Commun., 2019, 10, 612.

50 R. V. Mikhaylovskiy, T. J. Huisman, V. A. Gavrichkov, S. I. Polukeev, S. G. Ovchinnikov, D. Afanasiev, R. V. Pisarev, T. Rasing and A. V. Kimel, Phys. Rev. Lett., 2020, 125, 157201.

51 B. Koopmans, M. Van Kampen, J. T. Kohlhepp and W. J. M. De Jonge, Phys. Rev. Lett., 2000, 85, 844-847.

52 B. Koopmans, G. Malinowski, F. Dalla Longa, D. Steiauf, M. Fähnle, T. Roth, M. Cinchetti and M. Aeschlimann, Nat. Mater., 2010, 9, 259-265.

53 J.-Y. Bigot, M. Vomir and E. Beaurepaire, Nat. Phys., 2009, 5, 515-520.

54 G. P. Zhang, W. Hübner, G. Lefkidis, Y. Bai and T. F. George, Nat. Phys., 2009, 5, 499-502.
55 J. K. Dewhurst, S. Shallcross, P. Elliott, S. Eisebitt, C. V. K. Schmising and S. Sharma, 2020, arXiv:2012.03657 [cond-mat.mtrl-sci].

56 C. Dornes, Y. Acremann, M. Savoini, M. Kubli, M. J. Neugebauer, E. Abreu, L. Huber, G. Lantz, C. A. F. Vaz, H. Lemke, E. M. Bothschafter, M. Porer, V. Esposito, L. Rettig, M. Buzzi, A. Alberca, Y. W. Windsor, P. Beaud, U. Staub, D. Zhu, S. Song, J. M. Glownia and S. L. Johnson, Nature, 2019, 565, 209-212.

57 C. E. Graves, A. H. Reid, T. Wang, B. Wu, S. de Jong, K. Vahaplar, I. Radu, D. P. Bernstein, M. Messerschmidt, L. Müller, R. Coffee, M. Bionta, S. W. Epp, R. Hartmann, A. V. Kimel, G. Hauser, A. Hartmann, P. Holl, H. Gorke, J. H. Mentink, A. Tsukamoto, A. Fognini, J. J. Turner, W. F. Schlotter, D. Rolles, H. Soltau, L. Strüder, Y. Acremann, A. Kirilyuk, T. Rasing, J. Stöhr, A. O. Scherz and H. A. Dürr, Nat. Mater., 2013, 12, 293-298.

58 E. Iacocca, T. M. Liu, A. H. Reid, Z. Fu, S. Ruta, P. W. Granitzka, E. Jal, S. Bonetti, A. X. Gray, C. E. Graves, R. Kukreja, Z. Chen, D. J. Higley, T. Chase, L. Le Guyader, K. Hirsch, H. Ohldag, W. F. Schlotter, G. L. Dakovski, G. Coslovich, M. C. Hoffmann, S. Carron, A. Tsukamoto, A. Kirilyuk, A. V. Kimel, T. Rasing, J. Stohr, R. F. L. Evans, T. Ostler, R. W. Chantrell, M. A. Hoefer, T. J. Silva and H. A. Durr, Nat. Commun., 2019, 10, 1756.

59 B. Pfau, S. Schaffert, L. Muller, C. Gutt, A. Al-Shemmary, F. Buttner, R. Delaunay, S. Dusterer, S. Flewett, R. Fromter, J. Geilhufe, E. Guehrs, C. M. Gunther, R. Hawaldar, M. Hille, N. Jaouen, A. Kobs, K. Li, J. Mohanty, H. Redlin, W. F. Schlotter, D. Stickler, R. Treusch, B. Vodungbo, M. Klaui, H. P. Oepen, J. Luning, G. Grubel and S. Eisebitt, Nat. Commun., 2012, 3, 1100.

60 B. Vodungbo, J. Gautier, G. Lambert, A. B. Sardinha, M. Lozano, S. Sebban, M. Ducousso, W. Boutu, K. Li, B. Tudu, M. Tortarolo, R. Hawaldar, R. Delaunay, V. Lopez-Flores, J. Arabski, C. Boeglin, H. Merdji, P. Zeitoun and J. Luning, Nat. Commun., 2012, 3, 999.

61 P. Tengdin, C. Gentry, A. Blonsky, D. Zusin, M. Gerrity, L. Hellbrück, M. Hofherr, J. Shaw, Y. Kvashnin, E. K. Delczeg-Czirjak, M. Arora, H. Nembach, T. J. Silva, S. Mathias, M. Aeschlimann, H. C. Kapteyn, D. Thonig, K. Koumpouras, O. Eriksson and M. M. Murnane, Sci. Adv., 2020, 6, eaaz1100.

62 K. Yao, F. Willems, C. von Korff Schmising, C. Strüber, P. Hessing, B. Pfau, D. Schick, D. Engel, K. Gerlinger, M. Schneider and S. Eisebitt, Rev. Sci. Instrum., 2020, 91, 093001.

63 K. Bühlmann, G. Saerens, A. Vaterlaus and Y. Acremann, Sci. Rep., 2020, 10, 12632.

64 M. Plötzing, R. Adam, C. Weier, L. Plucinski, S. Eich, S. Emmerich, M. Rollinger, M. Aeschlimann, S. Mathias and C. M. Schneider, Rev. Sci. Instrum., 2016, 87, 043903.

65 J. S. Miller and A. J. Epstein, MRS Bull., 2000, 21-30.

66 S.-I. Ohkoshi, K. Imoto, Y. Tsunobuchi, S. Takano and H. Tokoro, Nat. Chem., 2011, 3, 564-569.

67 S.-I. Ohkoshi and H. Tokoro, Acc. Chem. Res., 2012, 45, 1749-1758. 
68 M. Verdaguer, A. Bleuzen, V. Marvaud, J. Vaissermann, M. Seuleiman, C. Desplanches, A. Scuiller, C. Train, R. Garde, G. Gelly, C. Lomenech, I. Rosenman, P. Veillet, C. Cartier and F. Villain, Coord. Chem. Rev., 1999, 190-192, 1023-1047.

69 S. Ferlay, T. Mallah, R. Ouahès, P. Veillet and M. Verdaguer, Nature, 1995, 378, 701-703.

70 M. Verdaguer, A. Bleuzen, C. Train, R. Garde, F. Fabrizi de Biani and C. Desplanches, Philos. Trans. R. Soc., A, 1999, 357, 2959-2976.

71 O. Sato, T. Iyoda, A. Fujishima and K. Hashimoto, Science, 1996, 271, 49-51.

72 S.-I. Ohkoshi, T. Iyoda, A. Fujishima and K. Hashimoto, Phys. Rev. B: Condens. Matter Mater. Phys., 1997, 56, 11642-11652.

73 Y. Sato, S.-I. Ohkoshi, K.-I. Arai, M. Tozawa and K. Hashimoto, J. Am. Chem. Soc., 2003, 125, 14590-14595.

74 S.-I. Ohkoshi, K. Nakagawa, K. Tomono, K. Imoto, Y. Tsunobuchi and H. Tokoro, J. Am. Chem. Soc., 2010, 132, 6620-6621.

75 S.-I. Ohkoshi, A. Fujishima and K. Hashimoto, J. Am. Chem. Soc., 1998, 120, 5349-5350.

76 M. Mizuno, S.-I. Ohkoshi and K. Hashimoto, Adv. Mater., 2000, 8904, 1955-1958.

77 M. Reczyński, K. Nakabayashi and S.-I. Ohkoshi, Eur. J. Inorg. Chem., 2020, 2669-2678.

78 S.-I. Ohkoshi, Y. Einaga, A. Fujishima and K. Hashimoto, J. Electroanal. Chem., 1999, 473, 245-249.

79 O. Sato, Y. Einaga, A. Fujishima and K. Hashimoto, Inorg. Chem., 1999, 38, 4405-4412.

80 A. Bleuzen, C. Lomenech, V. Escax, F. Villain, F. Varret, C. Cartier dit Moulin and M. Verdaguer, J. Am. Chem. Soc., 2000, 122, 6648-6652.

81 D. M. Pajerowski, M. J. Andrus, J. E. Gardner, E. S. Knowles, M. W. Meisel and D. R. Talham, J. Am. Chem. Soc., 2010, 132, 4058-4059.

82 O. Sato, J. Solid State Electrochem., 2007, 11, 773-779.

83 L. Hedley, N. Robertson and J. O. Johansson, Electrochim. Acta, 2017, 236, 97-103.

84 M. Verdaguer, M. Glavez, R. Garde and C. Desplanches, Electrochem. Soc. Interface, 2002, 11, 28.

85 Y. Huang and S. Ren, Appl. Mater. Today, 2021, 22, 100886.

86 M. B. Zakaria and T. Chikyow, Coord. Chem. Rev., 2017, 352, 328-345.

87 T. Nuida, T. Hozumi, W. Kosaka, S. Sakurai, S. Ikeda, T. Matsuda, H. Tokoro, K. Hashimoto and S.-I. Ohkoshi, Polyhedron, 2005, 24, 2901-2905.

88 S.-I. Ohkoshi, M. Mizuno, G.-J. Hung and K. Hashimoto, J. Phys. Chem. B, 2000, 104, 9365-9367.

89 Y. Sato, S.-I. Ohkoshi and K. Hashimoto, J. Appl. Phys., 2002, 92, 4834.

90 E. Coronado, M. Makarewicz, J. P. Prieto-Ruiz, H. PrimaGarcia and F. M. Romero, Adv. Mater., 2011, 23, 4323-4326.

91 E. Coronado, J. P. Prieto-Ruiz and H. Prima-Garcia, Chem. Commun., 2013, 49, 10145.

92 H. Prima-Garcia, E. Coronado, J. P. Prieto-Ruiz and F. M. Romero, Nanoscale Res. Lett., 2012, 7, 232.
93 W. E. Buschmann, S. C. Paulson, C. M. Wynn, M. A. Girtu, A. J. Epstein, H. S. White and J. S. Miller, Chem. Mater., 1998, 10, 1386-1395.

94 J. P. Prieto-Ruiz, F. M. Romero, H. Prima-García and E. Coronado, J. Mater. Chem. C, 2015, 3, 11122-11128.

95 L. Hedley, L. Porteous, D. Hutson, N. Robertson and J. O. Johansson, J. Mater. Chem. C, 2018, 6, 512-517.

96 D. R. Talham and M. W. Meisel, Chem. Soc. Rev., 2011, 40, 3356-3365.

97 A. Eschenlohr, M. Battiato, P. Maldonado, N. Pontius, T. Kachel, K. Holldack, R. Mitzner, A. Föhlisch, P. M. Oppeneer and C. Stamm, Nat. Mater., 2013, 12, 332-336.

98 A. Bleuzen, V. Marvaud, C. Mathonière, B. Sieklucka and M. Verdaguer, Inorg. Chem., 2009, 48, 3453-3466.

99 S.-I. Ohkoshi and K. Hashimoto, J. Photochem. Photobiol., C, 2001, 2, 71-88.

100 H. Tokoro and S. Ohkoshi, Dalton Trans., 2011, 40, 6825-6833. 101 O. Sato, Nat. Chem., 2016, 8, 644-656.

102 A. Asahara, M. Nakajima, R. Fukaya, H. Tokoro, S.-I. Ohkoshi and T. Suemoto, Phys. Rev. B: Condens. Matter Mater. Phys., 2012, 86, 195138.

103 M. B. Robin and P. Day, Adv. Inorg. Chem. Radiochem., 1968, 10, 247-422.

104 B. Mayoh and P. Day, J. Chem. Soc., Dalton Trans., 1974, 846. 105 P. J. Reid, C. Silva, P. F. Barbara, L. Karki and J. T. Hupp, J. Phys. Chem., 1995, 99, 2609-2616.

106 P. Kambhampati, D. H. Son, T. W. Kee and P. F. Barbara, J. Phys. Chem. A, 2000, 104, 10637-10644.

107 D. H. Son, P. Kambhampati, T. W. Kee and P. F. Barbara, J. Phys. Chem. A, 2002, 106, 4591-4597.

108 M. Thoss and H. Wang, Chem. Phys. Lett., 2002, 358, 298-306.

109 C. Wang, B. K. Mohney, B. B. Akhremitchev and G. C. Walker, J. Phys. Chem. A, 2000, 104, 4314-4320.

110 K. M. Slenkamp, M. S. Lynch, J. F. Brookes, C. C. Bannan, S. L. Daifuku and M. Khalil, Struct. Dyn., 2016, 3, 023609.

111 S. D. Su, X. Q. Zhu, L. T. Zhang, Y. Y. Yang, Y. H. Wen, X. T. Wu, S. Q. Yang and T. L. Sheng, Dalton Trans., 2019, 48, 9303-9309.

112 M. S. Lynch, B. E. Van Kuiken, S. L. Daifuku and M. Khalil, J. Phys. Chem. Lett., 2011, 2, 2252-2257.

113 M. S. Lynch, K. M. Slenkamp and M. Khalil, J. Chem. Phys., 2012, 136, 241101.

114 B. P. Macpherson, P. V. Bernhardt, A. Hauser, S. Pagès and E. Vauthey, Inorg. Chem., 2005, 44, 5530-5536.

115 O. Sato, T. Iyoda, A. Fujishima and K. Hashimoto, Science, 1996, 272, 704-745.

116 J. Zimara, H. Stevens, R. Oswald, S. Demeshko, S. Dechert, R. A. Mata, F. Meyer and D. Schwarzer, Inorg. Chem., 2021, 60, 449-459.

117 M. B. Robin, Inorg. Chem., 1962, 1, 337-342.

118 D. M. Rogers and J. O. Johansson, J. Mater. Sci. Eng. B, 2018, 227, 28-38.

119 M. van Veenendaal, Sci. Rep., 2017, 7, 6672.

120 S. Watanabe, Y. Sawada, M. Nakaya, M. Yoshino, T. Nagasaki, T. Kameyama, T. Torimoto, Y. Inaba, H. Takahashi, K. Takeshita and J. Onoe, J. Appl. Phys., 2016, 119, 235102. 
121 M. Cammarata, S. Zerdane, L. Balducci, G. Azzolina, S. Mazerat, C. Exertier, M. Trabuco, M. Levantino, R. AlonsoMori, J. M. Glownia, S. Song, L. Catala, T. Mallah, S. F. Matar and E. Collet, Nat. Chem., 2021, 13, 10-14.

122 D. C. Arnett, P. Voehringer and N. F. Scherer, J. Am. Chem. Soc., 1995, 117, 12262-12272.

123 K. Wynne and R. M. Hochstrasser, Chem. Phys., 1993, 171, 179-188.

124 A. T. Yeh, C. V. Shank and J. K. McCusker, Science, 2000, 289, 935-938.

125 S. Wallin, J. Davidsson, J. Modin and L. Hammarstrom, J. Phys. Chem. A, 2005, 109, 4697-4704.

126 S. N. Ghosh, J. Inorg. Nucl. Chem., 1974, 36, 2465-2466.

127 D. Weidinger, D. J. Brown and J. C. Owrutsky, J. Chem. Phys., 2011, 134, 124510.

128 D. Hayes, R. G. Hadt, J. D. Emery, A. A. Cordones, A. B. F. Martinson, M. L. Shelby, K. A. Fransted, P. D. Dahlberg, J. Hong, X. Zhang, Q. Kong, R. W. Schoenlein and L. X. Chen, Energy Environ. Sci., 2016, 9, 3754-3769.

129 N. Shimamoto, S. I. Ohkoshi, O. Sato and K. Hashimoto, Inorg. Chem., 2002, 41, 678-684.

130 H. Kamioka, Y. Moritomo, W. Kosaka and S.-I. Ohkoshi, Phys. Rev. B: Condens. Matter Mater. Phys., 2008, 77, 180301.

131 Y. Moritomo, H. Kamioka, T. Shibata, S. Nozawa, T. Sato and S. I. Adachi, J. Phys. Soc. Jpn., 2013, 82, 033601.

132 Y. Fukuyama, N. Yasuda, H. Kamioka, J. Kim, T. Shibata, H. Osawa, T. Nakagawa, H. Murayama, K. Kato, Y. Tanaka, S. Kimura, T. Ohshima, H. Tanaka, M. Takata and Y. Moritomo, Appl. Phys. Express, 2010, 3, 016601.

133 S. Zerdane, M. Cammarata, L. Balducci, R. Bertoni, L. Catala, S. Mazerat, T. Mallah, M. N. Pedersen, M. Wulff, K. Nakagawa, H. Tokoro, S.-I. Ohkoshi and E. Collet, Eur. J. Inorg. Chem., 2018, 272-277.

134 L. Trinh, S. Zerdane, S. Mazérat, N. Dia, D. Dragoe, C. Herrero, E. Rivière, L. Catala, M. Cammarata, E. Collet and T. Mallah, Inorg. Chem., 2020, 59, 13153-13161.

135 A. Simonov, T. De Baerdemaeker, H. L. B. Bostrom, M. L. Rios Gomez, H. J. Gray, D. Chernyshov, A. Bosak, H. B. Burgi and A. L. Goodwin, Nature, 2020, 578, 256-260.

136 M. Van Veenendaal, Phys. Rev. B: Condens. Matter Mater. Phys., 2018, 97, 125108.

137 H. Tokoro, S.-I. Ohkoshi and K. Hashimoto, Appl. Phys. Lett., 2003, 82, 1245.

138 H. Tokoro and S.-I. Ohkoshi, Bull. Chem. Soc. Jpn., 2015, 88, 227-239.

139 S.-I. Ohkoshi, H. Tokoro and E. Collet, C. R. Chim, 2019, 22, 498-507.

140 G. Azzolina, E. Collet, C. Mariette, M. Cammarata, E. Trzop, M. Sander, M. Levantino, K. Nakagawa, H. Tokoro, S.I. Ohkoshi and R. Bertoni, Eur. J. Inorg. Chem., 2019, 3142-3147.

141 S. I. Ohkoshi, T. Nuida, T. Matsuda, H. Tokoro and K. Hashimoto, J. Mater. Chem., 2005, 15, 3291-3295.

142 H. Tokoro, T. Matsuda, T. Nuida, Y. Moritomo, K. Ohoyama, E. D. L. Dangui, K. Boukheddaden and S.-I. Ohkoshi, Chem. Mater., 2008, 20, 423-428.
143 H. Tokoro, T. Matsuda, K. Hashimoto and S.-I. Ohkoshi, J. Appl. Phys., 2005, 97, 10m508.

144 R. Fukaya, A. Asahara, S. Ishige, M. Nakajima, H. Tokoro, S.-I. Ohkoshi and T. Suemoto, J. Chem. Phys., 2013, 139, 084303.

145 H. Tokoro, K. Nakagawa, K. Imoto, F. Hakoe and S. I. Ohkoshi, Chem. Mater., 2012, 24, 1324-1330.

146 R. Garde, F. Villain and M. Verdaguer, J. Am. Chem. Soc., 2002, 124, 10531-10538.

147 J. O. Johansson, J. W. Kim, E. Allwright, D. M. Rogers, N. Robertson and J.-Y. Bigot, Chem. Sci., 2016, 7, 7061-7067.

148 K. D. Bozdag, J.-W. Yoo, N. P. Raju, A. C. McConnell, J. S. Miller and A. J. Epstein, Phys. Rev. B: Condens. Matter Mater. Phys., 2010, 82, 094449.

149 L. Hedley, M. D. Horbury, F. Liedy and J. O. Johansson, Chem. Phys. Lett., 2017, 687, 125-130.

150 Q. Zhang, A. V. Nurmikko, G. X. Miao, G. Xiao and A. Gupta, Phys. Rev. B: Condens. Matter Mater. Phys., 2006, 74, 064414.

151 R. D. Averitt and A. J. Taylor, J. Phys.: Condens. Matter, 2002, 14, R1357-R1390.

152 A. Kirilyuk, A. V. Kimel and T. Rasing, Rev. Mod. Phys., 2010, 82, 2731-2784.

153 T. Ogasawara, M. Matsubara, Y. Tomioka, M. KuwataGonokami, H. Okamoto and Y. Tokura, Phys. Rev. B: Condens. Matter Mater. Phys., 2003, 68, 180407(R).

154 A. V. Kimel, R. V. Pisarev, J. Hohlfeld and T. Rasing, Phys. Rev. Lett., 2002, 89, 287401.

155 S. Otto, M. Dorn, C. Förster, M. Bauer, M. Seitz and K. Heinze, Coord. Chem. Rev., 2018, 359, 102-111.

156 V. G. Sala, S. Dal Conte, T. A. Miller, D. Viola, E. Luppi, V. Véniard, G. Cerullo and S. Wall, Phys. Rev. B: Condens. Matter Mater. Phys., 2016, 94, 014430.

157 F. Guo, N. Zhang, W. Jin and J. Chang, J. Chem. Phys., 2017, 146, 244502.

158 D. Giovanni, H. Ma, J. Chua, M. Grätzel, R. Ramesh, S. Mhaisalkar, N. Mathews and T. C. Sum, Nano Lett., 2015, 15, 1553-1558.

159 P. Somani and S. Radhakrishnan, Mater. Chem. Phys., 2002, 76, 15-19.

160 S. Ravaine, C. Lafuente and C. Mingotaud, Langmuir, 1998, 14, 6347-6349.

161 O. N. Risset, T. V. Brinzari, M. W. Meisel and D. R. Talham, Chem. Mater., 2015, 27, 6185-6188.

162 P. Perlepe, I. Oyarzabal, A. Mailman, M. Yquel, M. Platunov, I. Dovgaliuk, M. Rouzières, P. Négrier, D. Mondieig, E. A. Suturina, M.-A. Dourges, S. Bonhommeau, R. A. Musgrave, K. S. Pedersen, D. Chernyshov, F. Wilhelm, A. Rogalev, C. Mathonière and R. Clérac, Science, 2020, 370, 587-592.

163 F.-S. Guo, B. M. Day, Y.-C. Chen, M.-L. Tong, A. Mansikkamäki and R. A. Layfield, Angew. Chem., Int. Ed., 2017, 56, 11445-11449.

164 C. A. P. Goodwin, F. Ortu, D. Reta, N. F. Chilton and D. P. Mills, Nature, 2017, 548, 439-442.

165 F. S. Guo, B. M. Day, Y. C. Chen, M. L. Tong, A. Mansikkamaki and R. A. Layfield, Science, 2018, 362, 1400-1403. 